\title{
LOS PUERTOS DE LA PROVINCIA DE CORRIENTES. ORGANIZACIÓN, EQUIPAMIENTO Y ACTIVIDAD COMERCIAL (1816-1855)
}

\author{
Ports from the province of Corrientes. \\ Organization, equipment, and commercial activity (1816-1855)
}

Enrique César Schaller*

\section{Resumen}

En este artículo se estudia la organización y funcionamiento del sistema portuario de la provincia de Corrientes desde 1816 hasta 1855. Se examina el establecimiento de los puertos como parte del proceso de formación territorial y crecimiento económico del distrito. Se describe la legislación que regulaba la actividad de estos centros y su equipamiento. En base a los registros para la percepción de los impuestos aduaneros se efectúa un cálculo cuantitativo de la participación de cada uno de los puertos habilitados en el comercio de exportación e importación de la provincia.

$$
<\text { Corrientes }><\text { Comercio }><\text { Puertos }>
$$

\begin{abstract}
This article analyzes the organization and operation of the port system in the province of Corrientes from 1816 to 1855 . The foundation of ports is examined as part of the process of territorial formation and economic growth of the district. This paper also deals with the legislation regulating their activities and their equipment. Based on records for the collection of customs duties, a quantitative estimate of the participation of each of the authorized trade export and import ports of the province is made.
\end{abstract}

$<$ Corrientes $><$ Commerce $><$ Ports $>$

Recibido: 30/03/15 // Aceptado: 30/07/15

\footnotetext{
* Instituto de Investigaciones Geohistóricas- UNNE-CONICET. schaller53@gmail.com
} 


\section{Introducción}

A partir de las últimas décadas del período colonial la región rioplatense experimentó un acelerado crecimiento económico debido a la expansión del comercio de productos pecuarios con los mercados de ultramar. La vinculación con el exterior, como es sabido, se acentuó a partir de la declaración de la independencia y de la apertura comercial que fue consecuencia de la misma. Este proceso general de crecimiento ligado con el comercio afectó, en distinto grado, a las diversas comarcas de la región. De esta forma, también la economía de la jurisdicción de la ciudad de Corrientes, convertida en provincia autónoma en 1814, progresó de acuerdo con el desarrollo del intercambio. Se produjo un avance temprano en la etapa colonial pero desde la década de 1830 el distrito comenzó a quedar rezagado en relación con sus vecinos del Litoral, particularmente Entre Ríos, debido a las limitaciones ecológicas de la provincia para la actividad ganadera. (Wentzel, 1988; Rosal y Schmit, 1994). Por otra parte el papel dinámico del comercio estuvo fuertemente condicionado por los conflictos de intereses derivados principalmente de la fuerte dependencia de las zonas interiores con respecto del puerto de Buenos Aires (Whigham, 2009). Hay que señalar que el desarrollo comercial y productivo desde mediados del siglo XVIII involucró también un proceso de expansión territorial con la incorporación de nuevas tierras para las estancias (Maeder, 1981). El crecimiento de la jurisdicción, que se prolongó hasta fines del siglo XIX, constituyó uno de los rasgos centrales de la evolución de Corrientes en este período con significativas consecuencias desde el punto de vista económico, social e institucional. Una de ellas fue la formación de la provincia autónoma. En este aspecto, se ha destacado el papel del centro urbano cabecera, la ciudad de Corrientes, en la conformación de la nueva entidad política. Por su situación favorable en la ruta fluvial del río Paraná concentró la actividad comercial y política de una jurisdicción en constante crecimiento. Fue la cabecera mercantil a través de la cual se movilizaban las producciones de la zona rural mediante una red de intercambios y de financiamiento controlado por la élite urbana (Chiaramonte, 1991). Sin embargo, desde épocas tempranas, con la rápida ampliación del territorio el control de la ciudad de Corrientes sobre las zonas rurales tendió a debilitarse. Surgieron nuevos centros, como Goya y Curuzú Cuatiá, con cierta autonomía. Se fue configurando así una diferenciación regional entre una zona de antiguo poblamiento, de economía diversificada, y las áreas de ocupación más reciente, con especialización ganadera. Las derivaciones de estas diferencias en la vida políticoinstitucional de la provincia durante el siglo XIX han sido estudiadas (Gómez, 1928; Buchbinder, 2004), así como sus efectos demográficos (Maeder, 1969). Sin embargo, poco se ha tratado sobre la evolución productiva y mercantil de las regiones en esa etapa. Para abordar este aspecto el presente trabajo examina la evolución del valor y composición del comercio en los puertos habilitados para el tráfico exterior de la provincia de Corrientes sobre los ríos Paraná y Uruguay. La actividad de estos centros refleja en gran medida la evolución económica de su área de influencia lo que permite apreciar la diversidad de producciones y los diferentes ritmos de crecimiento regional. ${ }^{1}$

1 Diversos estudios (Chiaramonte, 1991; Rivera, 1981; Whigham, 2009) aportan valiosa información cuantitativa sobre el comercio de exportación de la ciudad de Corrientes, no contamos con datos similares 
El período elegido (1816-1855) comprende el lapso en que el gobierno correntino tuvo a su cargo la administración exclusiva de los puertos. Para un mejor conocimiento de las condiciones en que se desarrollaba su actividad se estudia además la formación de los mismos durante el avance territorial, la legislación que regulaba su actividad y su administración y equipamiento.

\section{Fuentes sobre el comercio exterior de la provincia de Corrientes}

Las series estadísticas de este trabajo se elaboraron en base a la información de las guías emitidas por las autoridades correntinas para la percepción de impuestos. Cuando se organizaron las provincias, tras el derrumbe de la estructura virreinal, los nuevos estados habilitaron aduanas en sus territorios con el fin de recaudar una escala variable de impuestos por los productos que ingresaban a sus jurisdicciones y por los que se exportaban de las mismas. En la provincia de Corrientes la primera tarifa aduanera entró en vigencia a partir del 9 de septiembre de 1815. Por ese motivo desde esa fecha se cuenta con registros bastante completos sobre el comercio con otras regiones. Los mismos se extienden hasta mediados de 1855, momento en que se produjo la transferencia de las aduanas fluviales a la jurisdicción nacional. ${ }^{2}$

En las guías se consigna con precisión la cantidad de bienes comercializados (por unidad, peso o longitud según el producto), el destino de los mismos, los comerciantes que realizan la operación y el impuesto que debía abonarse. Sin embargo, la información es más limitada en relación con el valor monetario de los productos, dato fundamental para el análisis del movimiento comercial. De manera similar a otras provincias, en Corrientes los bienes estaban gravados por impuestos proporcionales al valor de plaza o por derechos específicos (sumas fijas). En el primer caso, la guía contiene el aforo, es decir, el cálculo del precio corriente del producto. Por ese motivo el valor de las importaciones es fácil de determinar pues casi todos los bienes estaban sujetos al pago de un derecho proporcional. En el caso de las exportaciones este cálculo es más complicado pues los artículos más valiosos del comercio exterior correntino

sobre las otras localidades que servían sobre todo a las zonas ganaderas.

2 En el Archivo General de la Provincia de Corrientes las guías se hallan agrupadas en dos series documentales. Los Comprobantes de Libros de Caja reúnen las guías de la aduana de la ciudad de Corrientes. Las que corresponden a las receptorías que funcionaron en otras localidades se encuentran en los Expedientes Administrativos. Comprobantes libros de Caja: legajos no 1 (1815-1818), 2 (1819-1820), 3 (1821), 4 (1822), 5-6 (1823), 7-8 (1824-1825), 9 (1826), 10-12 (1827-1828), 13-16 (1829), 17-18 (1830), 19 (1831), 20-21 (1832), 22-23 (1833), 24-28 (1834-1835)),29-31 (1836) 32-33 (1837), 34-35 (1838), 36-37 (1839), 38-39 (1840), 40-43 (1841-1842), 44-48 (1843), 47 (1844), 49-51 (1845), 52-53 (1846), 54-56 (1847). 57-60 (1849), 58-61 (1848), 62-63 (1850), 64-65 (1851), 66-68 (1852)), 69-70 (1853), 71-72 (1854), 73 (1855).

Expedientes Administrativos: legajo no 1 (1810-1812), 2 (1813-1816), 3 (1817), 4 (1818-1819), 5 (1820), 6 (1821), 7-8 (1822), 9-10 (1823), 11-12 (1824), 13-14 (1825), 15-18 (1826), 19-22 (1827), 23-25 (18281829), 26-29 (1830), 30-32 (1831), 33-35 (1832), 36-38 (1833), 39-42 (1834), 43-47 (1835), 48-49 (1836), 50-53 (1837), 54-57 (1838), 58 (1839), 59-60 (1840), 61-65 (1841), 66 (1842), 67-69 (1843), 70-73 (1844), 74-78 (1845), 79-85 (1846), 86-90 (1847), 90-94 (1848), 95-101 (1849), 102-105 (1850), 106-109 (1851), 110-113 (1852), 114-116 (1853), 117 (1854). 
(cueros, suelas, maderas, tabaco y animales en pie) quedaron sujetos a impuestos fijos. Las guías del período 1822-1836 prácticamente no ofrecen referencias sobre el valor de esos productos. Para la etapa posterior, los datos son más completos aunque todavía subsisten vacíos en la información. ${ }^{3}$

Debido a estas lagunas sólo es posible efectuar una estimación aproximada del valor de los frutos no aforados. Para establecerlo, en este trabajo se considera que el impuesto específico representaba 1/8 (12,5\%) del valor de esos bienes. Esta proporción se ha establecido en relación con los precios de algunos artículos, en especial cueros $\mathrm{y}$ animales en pie, que aparecen en los inventarios y algunas transacciones al por mayor del gobierno. Los derechos fijos de aquellos bienes que tenían algún proceso de elaboración, como los cueros curtidos, representarían el 6,25\% o un 1/16 del valor. La utilización de estos valores de referencia, por supuesto, constituye sólo un instrumento alternativo de análisis ante la falta de datos sobre los precios reales. Debe señalarse finalmente que los valores están expresados en pesos plata de ocho reales. ${ }^{4}$

\section{La formación de los puertos de la provincia de Corrientes}

El surgimiento de los puertos sobre la ribera de los ríos Paraná y Uruguay constituyó un aspecto de la formación territorial y de poblamiento de la provincia de Corrientes. La jurisdicción, como es sabido, integra la Mesopotamia argentina vasta llanura encerrada entre los ríos Paraná y Uruguay. Uno de los rasgos geográficos más destacables de la provincia es el área deprimida del centro donde se asienta la cuenca del Iberá, zona de lagunas, esteros y bañados que abarca alrededor de 13.000 km2 y constituye un enorme obstáculo para las comunicaciones interiores. Divide el sector occidental, que corresponde a la cuenca del río Paraná, de su mitad oriental, perteneciente a la vertiente del Uruguay. La conexión entre ambas áreas tiene lugar en el norte mediante una estrecha franja de terreno elevado entre el río Paraná y el Iberá. Otra zona de vinculación es la planicie del Paiubre, en el sur de la provincia, amplia comarca sin terrenos anegados con lomadas similares a las cuchillas entrerrianas. En la cuenca del Iberá se originan la mayor parte de los ríos interiores que desembocan en los grandes cursos fluviales. Los más importantes, como el Santa Lucía y el Corrientes en la

\footnotetext{
3 En 1837 se establecieron impuestos proporcionales para el tabaco y las maderas. Durante la década de 1840 los cueros, suelas y animales en pie del Paraguay que se exportaban por Corrientes abonaban un derecho de tránsito proporcional. También se cuenta con listas de precios de frutos en la ciudad de Corrientes, que se publicaron en los meses de abril y mayo de 1848 en el periódico Corrientes Confederada. Hay una lista similar para el año 1855 editada en El Comercio. Existen cálculos de la Colecturía de la provincia sobre el valor de las exportaciones e importaciones de 1825 hasta 1843 . La serie completa ha sido analizada por José Carlos Chiaramonte. Estos montos, sin embargo, son globales y no permiten analizar la composición del comercio exterior ni la participación de los diferentes puertos en el mismo. Cfr. Chiaramonte, 1991.

${ }^{4}$ Los valores estimados para los principales productos son los siguientes: cueros vacunos, 18 reales; cueros de bagual y de becerro, 4 reales; suelas, $\$ 5$; caballos: $\$ 2$, mulas: $\$ 4$; vacunos, $\$ 3$; tabaco, $\$ 4$ la arroba; cigarros $\$ 8$ la arroba. Cortes de madera por vara: vigas, $\$ 1$, trozo, $\$ 2$; tirantes: 4 reales; tirantillos: 1 real. Cortes de madera por unidad: maza, $\$ 3$, rayos, $\$ 1$.
} 
cuenca del Paraná y el Miriñay y el Aguapey, en la del Uruguay, constituyeron también en su momento las fronteras del avance correntino (Bruniard, 1966).

El río Paraná cumplió un papel decisivo como vía de ingreso de la colonización española y como principal ruta de intercambio y de comunicación. El centro más antiguo, la ciudad de Vera, integró la cadena de fundaciones que se realizaron durante las primeras etapas de la colonización española a lo largo del eje de los ríos Paraná y Paraguay. La ciudad se asentó el 3 de abril de 1588 sobre la ribera izquierda del Paraná en el sitio denominado de "las Siete Corrientes", por las puntas rocosas de la costa que se adentran en el curso fluvial. Con el tiempo el nombre de la ciudad se identificó con el del paraje. Se estableció como punto de escala para la navegación entre Asunción y las poblaciones del sur, Buenos Aires y Santa Fe. El lugar elegido reunía las condiciones adecuadas para esta función. Se ubica en el sector donde el curso del Paraná realiza una brusca curva y cambia su dirección general este-oeste por una orientación norte-sur. Las puntas de piedra forman ensenadas arenosas cómodas para desembarcaderos y abrigos de buques. A poca distancia del sitio, hacia el nordeste, se produce la confluencia de los ríos Paraná y Paraguay en el lugar denominado "Tres Bocas". Corrientes era así el paso obligado para los buques que ingresaban en la jurisdicción de Asunción o salían de ella (Gómez, 1944).

Mediante un lento proceso de ocupación el área de influencia de la ciudad se extendió sobre la campaña adyacente y a mediados del siglo XVIII abarcaba el sector noroeste del actual territorio provincial, extenso triángulo limitado al norte y al oeste por el río Paraná y al sudeste por el Santa Lucía. A partir la segunda mitad de la centuria, el avance se aceleró debido al extraordinario crecimiento demográfico y productivo de la jurisdicción. Entre 1760 y 1810 la población aumentó de 9.700 a 33.000 habitantes. La actividad ganadera se afianzó con la venta de hacienda al Paraguay y Misiones y, desde la década de 1790, con la exportación de cueros vacunos hacia Buenos Aires. El auge ganadero impulsó el avance de las estancias al sur del río Santa Lucía. El territorio de la jurisdicción se amplió de 18.000 km2 a 56.000 km2. A partir de la década de 1760 comenzó la ocupación de los sectores central y suroeste de la actual provincia hasta el río Guayquiraró. También desde 1770 el avance del poblamiento correntino se extendió al sureste por la región del Paiubre con una dirección general hacia la ribera del río Uruguay. Se llegó así a la frontera del río Miriñay que constituyó el límite extremo de la expansión hacia el Este en la etapa colonial. No se logró alcanzar la costa del Uruguay porque el área pertenecía a los pueblos guaraníes de Yapeyú y La Cruz de la provincia de Misiones (Maeder, 1981).

Como resultado del rápido avance territorial, la ciudad de Corrientes ya no estuvo en condiciones de centralizar la actividad mercantil de su distrito puesto que quedaba muy alejada de las nuevas áreas ganaderas. A lo largo de la extensa costa del Paraná se establecieron embarcaderos clandestinos que ahorraban el largo y costoso traslado hacia el puerto de Corrientes. Esta actividad comercial no autorizada dio origen, hacia 1790 aproximadamente, a las localidades de Goya y Esquina en el suroeste de la jurisdicción. En este sector la ribera es baja e inundable. Entre las zonas más elevadas del interior y 
el curso principal del río se extiende una ancha faja deprimida por donde se desplazan numerosos cursos secundarios. Las localidades se asentaron espontáneamente en los puntos donde las lomadas se acercan al cauce principal. Goya constituía el punto de contacto más directo de las tierras situadas en el centro y del sur de la jurisdicción. $\mathrm{Su}$ posición estratégica compensaba ampliamente las dificultades del sitio y la convirtió en poco tiempo en la cabecera mercantil de la nueva frontera ganadera. Esquina, por su parte, ocupaba una posición menos favorable ya que era el centro de intercambio de una zona aislada en el extremo suroeste. El Cabildo de la ciudad de Corrientes reclamó en repetidas oportunidades la clausura de estos puertos porque alegaba que el comercio sin control promovía el robo de hacienda y el faenamiento clandestino. Los intentos fueron infructuosos y finalmente las autoridades del Virreinato habilitaron los puertos con la instalación una receptoría en Goya (1802) y otra en Esquina (1803).

Durante la primera década del período independiente el régimen de los puertos fluviales se vio condicionado por la fragmentación territorial del Virreinato del Río de la Plata y los conflictos regionales. Como parte de este proceso en junio de 1814 la élite local proclamó la autonomía de Corrientes y se constituyó en provincia. En consecuencia, la administración de los puertos y la recaudación de los recursos en las receptorías, que antes dependían de Buenos Aires, quedaron bajo el control de las autoridades de la jurisdicción. Los primeros reglamentos que regularon el comercio exterior, (9 de septiembre de 1815, $1^{\circ}$ de diciembre de 1822, 26 de enero de 1825), mantuvieron como centros habilitados sobre el río Paraná a los puertos de Corrientes, Goya y Esquina. ${ }^{5}$

La nueva provincia se recuperó rápidamente de los desórdenes de la etapa inicial del período independiente. Durante la primera mitad del siglo XIX la población correntina creció de manera sostenida, salvo durante la etapa de luchas de la década de 1840. De esta forma, hacia 1857, la población del distrito era de poco más de 85.000 habitantes (Maeder, 1969). En la década de 1820 se reanudó el avance territorial y la formación de nuevas poblaciones. Un paso importante consistió en asegurar el dominio correntino sobre la costa del Paraná amenazada por los ataques de los indios del Chaco. Como parte de esta política Pedro Ferré (1824-1828) fundó las localidades de Bella Vista (1825) y Empedrado (1826). La primera de ellas, por ley del 17 de junio, fue habilitada como puerto para el comercio. ${ }^{6}$ Con este centro, situado sobre una barranca elevada de la costa, los departamentos interiores del noroeste podían contar con un nuevo punto para el tráfico fluvial. Años más tarde, por la ley de aduanas del 26 de

5 El texto del Reglamento de 1815 se reproduce en Hernán Gómez, El general Artigas y los hombres Corrientes, 1929, pp. 84-85. El arancel de 1822 en Archivo General de la Provincia de Corrientes, Documentación histórica. Años 1821 y 1822, Corrientes, 1928, p. 281; El Reglamento de 1825 en el Registro Oficial de la Provincia de Corrientes (en adelante RO), tomo I, 1821-1825, Corrientes, 1929, pp. 347-363.

${ }^{6} R O$, tomo I, $1821-1825$, p. 375. De acuerdo con la Constitución correntina de 1824, la habilitación de puertos al comercio exterior se efectuaba por medio de una ley del Congreso provincial. 
febrero de 1851, también se autorizó a Empedrado debido al extraordinario crecimiento de la explotación forestal en la vecina costa chaqueña. ${ }^{7}$

Mientras se consolidaba la presencia correntina sobre la costa del Paraná, también comenzaba el avance en la frontera oriental hacia la ribera del Alto Uruguay. Durante la década de 1820 la jurisdicción de la provincia Corrientes aún no alcanzaba la costa del río. El límite estaba definido por el río Miriñay y los esteros del Iberá hasta la localidad de Tranquera de Loreto. El punto más avanzado de la ocupación correntina era Curuzú Cuatiá, localidad interior en el sur de la provincia formada hacia 1799, adonde convergían los caminos más importantes que comunicaban las áreas pobladas del oeste con la costa del Uruguay. Por ley del 24 de diciembre de 1821 comenzó a funcionar allí una receptoría. ${ }^{8}$ Desde este punto se desarrollaba un incipiente tráfico con Brasil y el oriente entrerriano que atravesaba un territorio que aún se consideraba como perteneciente a los pueblos guaraníes de la provincia de Misiones. Estos últimos, sin embargo, estaban en la etapa final de su disolución.

El control efectivo por parte de Corrientes de una parte de la costa occidental del río Uruguay recién tuvo lugar con el convenio del 19 de abril de 1830. Por este acuerdo, los indios del pueblo de La Cruz "restos de la población que hubo en el territorio que se denominaba de Misiones Occidentales" aceptaron la autoridad del gobierno correntino. De esta forma la provincia tomó posesión del área comprendida entre el Miriñay y el Aguapey lo que implicaba la anexión de unos $30.000 \mathrm{~km} 2$. Las poblaciones se asentaron en las zonas más elevadas de la costa del Uruguay. El río corre encajonado y en varios puntos, denominados Pasos, la distancia entre ambas márgenes se estrecha lo que permite un fácil vadeo. Debido a las dificultades de control en esa zona semidespoblada, por un tiempo no se instalaron aduanas sobre la costa del Uruguay. El gobierno habilitó varios pasos sobre el río pero éstos constituían sólo lugares de tránsito, mientras que los impuestos se continuaron pagando en Curuzú Cuatiá. ${ }^{9}$ La situación cambió a raíz del largo conflicto que la provincia sostuvo con el gobernador de Buenos Aires, Juan Manuel de Rosas. Durante los años 1839 y 1847, Corrientes organizó tres movimientos contra el dictador porteño que fueron finalmente derrotados tras diversas alternativas (Mantilla, 1928). En ese lapso, salvo algunos breves períodos, la navegación del Paraná se volvió insegura ante el peligro de ataques y requisas. Las dificultades por la principal vía de comunicación aceleraron la habilitación de puertos sobre la costa del Uruguay. Por ley del 27 de febrero de 1839 la localidad de La Cruz se abrió al comercio exterior. Pero este centro, resto del antiguo poblamiento jesuítico en la zona, se hallaba demasiado alejado de los principales puntos de intercambio fronterizo por lo que su actividad fue insignificante. ${ }^{10}$

Recién con la formación de los pueblos de Paso de los Libres y de Santo Tomé se establecieron centros sobre la costa del Uruguay que desarrollaron una actividad

\footnotetext{
RO, tomo VI, 1847-1852, pp. 286-303.

$8 R O$, tomo I, 1821-1825, p. 54.

9 Por ley del 28 de septiembre de 1830 se habilitó el paso de Itaquí para el ingreso y salida de productos. Luego, la ley del 11 de diciembre, autorizó el de Santa Ana, donde se estableció una guardia de vigilancia. ${ }^{10} R O$, tomo IV, 1838-1841, pp. 61-62; 83-84 y 102.
} 
mercantil apreciable. La localidad de Paso de los Libres se fundó por ley del 9 de septiembre de 1843 en el denominado Rincón de San Jorge. En la ley de creación se habilitó este punto para el comercio y se ordenó la instalación de la correspondiente receptoría. Al año siguiente, en la orilla vecina se fundó la población brasileña de Uruguayana. ${ }^{11}$ El otro centro sobre la costa del Uruguay surgió en la frontera nordeste de la provincia en las cercanías del destruido pueblo misionero de Santo Tomé, frente a localidad brasileña de San Borja. Sobre el dominio del área existía una disputa jurisdiccional con el Paraguay que, en los años 1832 y 1834 llevó a un enfrentamiento entre ambos Estados. Al disminuir las tensiones comenzó a organizarse en ese punto un incipiente centro urbano. La firma de un tratado de límites con el Paraguay en 1841 arregló, al menos provisoriamente, la cuestión jurisdiccional y reconoció el dominio de Corrientes sobre este sector. A partir de julio de 1842 comenzó a funcionar una receptoría en Santo Tomé. Durante algunos años la actividad comercial fue muy intensa pero en 1849 el pueblo fue destruido al reanudarse la ocupación paraguaya (Centeno, 1980: 132-133; Palma, 1969).

La organización constitucional del país produjo un cambio fundamental en el manejo de los puertos. El Acuerdo de San Nicolás (mayo de 1852) creó una autoridad nacional provisoria y otorgó a la misma las rentas de las aduanas exteriores del país. Los principales puertos fluviales, entre ellos los de Corrientes, fueron abiertos al comercio de ultramar y la administración de los mismos debía quedar a cargo de la nueva autoridad nacional. Esta medida preliminar fue consagrada en forma definitiva por la Constitución Nacional (mayo de 1853) y debía ejecutarse a partir la instalación del gobierno presidido por Justo José de Urquiza (marzo de 1854). En la práctica el traspaso se demoró debido a las dificultades que se presentaron para organizar el sistema rentístico de la Nación. De esta forma la provincia conservó, con limitaciones, la administración de los puertos de su jurisdicción hasta mediados de 1855.

\section{La legislación sobre los puertos}

Durante la etapa virreinal la navegación de los ríos en la región rioplatense se concentraba en el eje Paraguay-Paraná. Esta vía integraba una sola entidad política lo cual facilitaba el intercambio. El comercio interno en el Virreinato estaba sujeto al pago de la alcabala, impuesto del $4 \%$ sobre el valor de los productos, que se abonaba una sola vez en el lugar de destino. A este derecho general, por lo común se agregaban impuestos locales (arbitrios, sisas) percibidos por los Cabildos con autorización de las autoridades coloniales. La vinculación del espacio fluvial rioplatense con los mercados de ultramar se efectuaba a través del puerto de Buenos Aires, habilitado por la corona española por el Reglamento de 1778. Esta localidad era el destino casi excluyente de los productos regionales y el centro de trasbordo de los efectos importados de ultramar hacia las zonas del interior.

${ }^{11} R O$, tomo V, 1842-1846, pp. 353-355. Entre 1848 y 1864 Paso de los Libres fue denominada Restauración. 
En el convulsionado período de 1810-1821 el proceso de división política tuvo un fuerte impacto en el tráfico fluvial. A partir de la ruptura con Buenos Aires en junio de 1810, las autoridades de Asunción asumieron el control exclusivo de la navegación por el rio Paraguay. La secesión paraguaya incrementó el valor estratégico del puerto de la ciudad de Corrientes que pasó a constituir un centro de avanzada en la frontera de la jurisdicción de las Provincias Unidas. Por su parte, la travesía del Paraná quedó repartida entre varias jurisdicciones. ${ }^{12}$ La fragmentación incrementó la carga impositiva dado que cada jurisdicción estableció su propia tarifa de derechos. Además entre estas unidades políticas se produjeron constantes enfrentamientos que se trasladaban con frecuencia al plano económico. Así la primera tarifa aduanera vigente en la provincia de Corrientes, el Reglamento Provisorio del 9 de septiembre de 1815, fijó fuertes recargos para los productos que provenían de Buenos Aires. Asimismo en dos oportunidades (18 de abril de 1819 y 2 de enero de 1821), la ciudad de Corrientes fue declarada "puerto preciso" para todos los buques que viajaban al Paraguay o venían del distrito con lo cual estaban obligados a recalar en el puerto correntino y pagar un derecho especial. ${ }^{13}$

Finalizadas las luchas del ciclo artiguista se estableció un nuevo equilibrio político que se expresó en sucesivos pactos que celebraron las provincias del Litoral en las décadas de 1820 y 1830 . Entre otros aspectos, buscaron establecer un régimen común para la navegación fluvial y el comercio. Si bien las provincias contratantes administraban los puertos de su jurisdicción se otorgaba a sus habitantes plena libertad de navegación. Se renunciaba así expresamente a la política de imponer "puertos precisos" para obtener ventajas económicas del tráfico de otros distritos. ${ }^{14}$ Esta libertad de navegación sólo se refería al intercambio interprovincial porque para el tráfico exterior permaneció vigente el régimen de la etapa colonial por el cual sólo el puerto de Buenos Aires estaba habilitado para el comercio de ultramar. Las provincias del Litoral reclamaron contra este privilegio porque las rentas de la aduana porteña eran administradas exclusivamente en beneficio de Buenos Aires pese a que todas contribuían con la venta de sus frutos. Demandaban la apertura de otros puertos fluviales y una participación en los ingresos (Burgin, 1975). ${ }^{15}$

\footnotetext{
${ }^{12}$ En el lapso de 1814 a 1819 se distribuía entre la Liga de Artigas y el Directorio de Buenos Aires, en 18201821 entre la "República Entrerriana", Santa Fe y Buenos Aires, y partir de 1822 entre las provincias de Buenos Aires, Santa Fe, Entre Ríos y Corrientes.

${ }^{13}$ Archivo General de la Provincia de Corrientes (en adelante AGPC), Expedientes Administrativos (EA), legajo 4. Reglamentos de Juan Bautista Méndez (1819) y Francisco Ramírez (1821); Duarte, 1966.

${ }^{14}$ En el Tratado del Cuadrilátero ( 25 de enero de 1822 ) se señalaba expresamente que los buques no podían ser "obligados a abonar derechos, descargar para vender sus mercaderías o frutos por pretexto alguno". Por su parte, el artículo $8^{\circ}$ del Pacto Federal (4 de enero de 1831) indicaba que los habitantes de las provincias litorales gozarían "recíprocamente la franqueza y seguridad de entrar y transitar con sus buques y cargas en todos los puertos, ríos y territorios de cada una". Cfr. Arbo, 1939.

15 Durante la ruptura con Buenos Aires entre 1839 y 1847 el estado correntino buscó establecer un contacto directo con las potencias de ultramar. La declaración más explícita en este sentido fue la ley del 23 de noviembre de 1841 por la cual se establecía que los navíos "despachados de los puertos de ultramar para esta provincia, serán considerados como buques correntinos despachados de puertos argentinos; y del mismo modo se considerarán sus cargamentos". La medida se justificaba porque "en el estado de inconstitución en que se halla la república, cada uno de los estados que la componen, tiene una existencia
} 
El monopolio del comercio exterior por parte del puerto de Buenos Aires fue uno de los motivos del enfrentamiento armado de la provincia contra Rosas durante la década de 1840. En este período crítico Corrientes afianzó los vínculos con los estados vecinos. El paso más importante en este aspecto fueron los tratados celebrados con el Paraguay el 31 de julio de 1841. En ellos se establecía "la amistad y recíproca libertad de comercio entre los súbditos de ambos gobiernos". Se determinaba como puntos de intercambio para el tráfico fluvial las ciudades de Corrientes y Pilar. Además se arreglaba provisoriamente el conflicto sobre la posesión de las tierras de las antiguas Misiones con lo cual la provincia podía acceder a la tradicional ruta comercial entre la localidad paraguaya de Itapúa (Encarnación desde 1842) y la brasileña de San Borja. Los acuerdos se mantuvieron hasta 1849 y en ese lapso la provincia cumplió el papel de intermediaria mercantil del Paraguay con el exterior por lo que los frutos de este país constituyeron un importante componente de las remesas correntinas (Scavone Yegros, 1995; Whigham, 2009; 112-113).

Hasta 1838 los únicos puertos de la provincia plenamente autorizados para el tráfico fluvial se ubicaron sobre el Paraná. El Reglamento General del 26 de enero de 1825 designaba a las localidades de Corrientes, Goya y Esquina para la importación de bienes y la exportación de frutos locales. El puerto de Bella Vista, habilitado en junio de ese año operó con restricciones hasta que la ley del 20 de septiembre de 1831 permitió que funcionara en las mismas condiciones que los otros puertos. ${ }^{16}$ En lo que respecta al tráfico sobre la costa del Uruguay, como se ha dicho, inicialmente la aduana se estableció en Curuzú Cuatiá, en el interior de la provincia. Entre esta localidad y los pasos habilitados sobre el río (Itaqui y Santa Ana) existía una vasta zona poco poblada muy difícil de controlar. Por ese motivo en esos puntos sólo estaba autorizada la importación de los frutos de producción propia de los estados limítrofes, es decir, de yerba brasileña. Esta limitación quedó expresamente establecida en la ley del 13 de mayo de 1831. Los efectos de ultramar sólo podían ingresar por los puertos del Paraná. En la práctica, algunas modestas partidas se introdujeron desde el nordeste de Entre Ríos, especialmente tras la fundación de Concordia (1832). ${ }^{17}$ Las restricciones sobre el comercio en la costa del Uruguay se dejaron de lado a fines de la década de 1830 debido las dificultades por las que atravesaba el tráfico por el Paraná. Por la ley del 20 de junio

política propia e independiente, en virtud de la que puede por sí resolver cuanto le concierna", $R O$, tomo IV, 1830-1841, Corrientes, 1928, pp. 359-360.

${ }^{16}$ Bella Vista en un principio sólo estuvo autorizado para exportar frutos locales. El decreto del 18 de junio de 1826 permitió la importación de efectos pero sólo de aquellos que, a juicio de las autoridades, fueran de "fácil reconocimiento". Como medida de fomento, por ley de 22 de octubre de 1825 , las salidas de productos agrícolas y maderas quedaban libres del pago de derechos por cuatro años. $R O$, tomo I, 18211825 , p. 405 ; $R O$, tomo II, 1826-1830, pp. 44-45; RO, tomo III, 1831-1837, pp. 86.

17 El gobernador Pedro Ferré en un oficio al Congreso provincial (15 de mayo de 1831) destacaba que la apertura del Paso de Santa Ana "no tenía otra tendencia que la de facilitar el comercio que pudieran prometer los frutos producidos por los Estados Brasileño y Oriental [y] de ningún modo debe entenderse para que por aquella vía se importen mercaderías que no sean legítimamente producidas por los Estados referidos, pues para los procedentes de las Provincias de la Unión y otros Países, tiene Corrientes sus respectivos puertos habilitados" AGPC, Copiadores Notas del Ministerio de Gobierno (CNMG), tomo III, Comunicaciones al congreso provincial.; RO, tomo III, 1831-1837, p. 25. 
de 1838 se autorizó a importar por los pasos de Higos y de Santa Ana "los efectos sea cual sea su procedencia, así como para exportar los frutos de la provincia”. A partir de ese momento los puntos habilitados sobre el Uruguay quedaron en iguales condiciones que los puertos del Paraná. ${ }^{18}$

Además de canalizar el comercio local los puertos funcionaban también como centros de depósito de mercaderías que ingresaban al territorio provincial pero estaban destinadas a otras jurisdicciones. El puerto de la ciudad de Corrientes, en particular, sirvió como escala intermedia en el comercio del Paraguay. De acuerdo con el reglamento de 1825 los bienes en tránsito estaban sujetos a un impuesto del $2 \%$ de su valor y podían almacenarse hasta noventa días. La disposición general sobre los depósitos fue suspendida por ley del 16 de febrero de 1827 "en calidad de por ahora" pero no fue restablecida hasta el 23 de noviembre de 1841 mediante una resolución similar dictada para facilitar el comercio con el Paraguay. ${ }^{19}$ Aunque de mucho menor volumen, también se desarrollaba un comercio de tránsito con el Brasil. Por decreto de 17 de septiembre de 1828 este intercambio se centralizó en el puerto de Esquina. Posteriormente mediante el decreto del 20 de junio de 1840 el punto de trasbordo se trasladó a la localidad de Goya. En el sector oriental de la provincia la receptoría de Curuzú Cuatiá controló la ruta desde el nordeste entrerriano. A partir de 1844 esta vigilancia se estableció en Paso de Los Libres. ${ }^{20}$

\section{Equipamiento y administración}

El Paraná constituía la ruta principal del comercio exterior para la provincia de Corrientes. Este río ancho y caudaloso, sin saltos ni rápidos en el extenso tramo que se extiende desde Apipé hasta su desembocadura, era la vía de comunicación más rápida y económica para el acceso hacia las otras poblaciones del Litoral, especialmente Buenos Aires. No obstante, la navegación presentaba dificultades por los continuos cambios en el cauce principal y la presencia de raigones y bancos de arena. Asimismo la costa en su curso medio e inferior no se presta para la formación de puertos (Kroeber, 1967).

En el tramo de la orilla izquierda que pertenecía a la jurisdicción de la provincia el sitio más adecuado para la actividad portuaria es el de la ciudad de Corrientes. Se trata de un lugar elevado con acceso directo al curso principal del río. Las características siete puntas rocosas, que sobresalen de la costa y que dieron lugar al nombre del paraje, formaban puertos naturales aptos para desembarco y abrigo de los buques. El naturalista Alcides D’Orbigny, quien visitó la provincia entre 1827 y 1828, destacaba que “El lado que da sobre el río es... el más pintoresco de la ciudad porque una multitud de ensenadas arenosas, formadas por las puntas de roca, ofrece, en todas partes pequeños puertos en su mayoría llenos de barcos" (D’Orbigny, 1955; 399-400). En un informe

\footnotetext{
${ }^{18} R O$, tomo IV, 1838-1841, pp. 61-62

${ }^{19}$ Posteriormente, la ley del 12 de enero de 1842 amplió el plazo de los depósitos a seis meses en vista de la incertidumbre que afectaba la navegación de los ríos. $R O$, tomo II, 1826-1830, p. 108; $R O$, tomo IV, 1838-1841, pp. 360-361; RO, tomo V, 1842-1846, p. 5

${ }^{20} R O$, tomo II, 1826-1830; $R O$, tomo IV, 1838-1841, p. 263.
} 
de 1853 se afirmaba que la capital contaba con diez fondeaderos naturales "en los cuales pueden cargar y descargar con planchada y bastante comodidad buques de hasta 200 toneladas". ${ }^{21}$ De las siete puntas, la más sobresaliente es la que se denomina San Sebastián, y desde allí se podía observar el movimiento en las ensenadas vecinas. La rada al Este del promontorio constituía el puerto principal donde descargaban los barcos más grandes, era, señalaba D’Orbigny, el centro del movimiento comercial, "es allí donde se aglomeran los marineros; es allí donde se amontonan las pilas de maderas y planchas, listas para enviarse a las provincias vecinas. Este lugar es, por así decirlo, una parte diferente de la ciudad" (D' Orbigny, 1955; 400). Para un mejor control, en enero de 1825 el gobierno estableció allí la descarga obligatoria de los buques. Años más tarde (24 de febrero de 1842), se habilitó otro punto situado un poco más al este, en el paraje La Rosada. ${ }^{22}$

A lo largo del año podían acceder al puerto de Corrientes todo tipo de embarcaciones utilizadas en la navegación fluvial. En los períodos de creciente (principalmente de enero a marzo) también estaban en condiciones de llegar sin grandes dificultades buques de mayor calado propios de la navegación de ultramar. Como lo señalaba Martín de Moussy, con esta ventaja la ciudad era "la más comerciante de la provincia" (Moussy, 1860, 135). ${ }^{23}$

Pese a las condiciones favorables el acceso a los desembarcaderos naturales de la ciudad no siempre era sencillo por la configuración de la costa y las corrientes caprichosas del río que dificultaban las maniobras de los buques de vela. En los períodos de calma, para sortear las salientes, debía recurrirse al expediente de atar cabos en piedras o árboles de la costa. En estas operaciones las embarcaciones podían ser arrastradas rio abajo o encallar. ${ }^{24}$ Las autoridades provinciales realizaron algunas obras

${ }^{21}$ Razón que se da al Ministerio de Hacienda Nacional con arreglo a la nota del 21 de noviembre del Corriente Año, $A G P C, E A$, leg. 117. El informe es del 16 de diciembre. Las puntas rocosas que encerraban los puertos naturales eran de este a oeste: Aldana, Yatictá, Batería, San Sebastián, Tacurú, Tacuara y Arazatí.

${ }^{22}$ Comunicación del gobernador al Colector General (18 de enero de 1825): "la poca delicadeza y exactitud de los introductores en la satisfacción de los derechos... reclaman con imperio un orden que haga desaparecer la quiebra que amenaza el Estado. Bajo este principio, ha resuelto que todo buque que en adelante llegue a estos Puertos con cargamento y procedente de cualesquiera destino que sea, aporte en la Banda Oriental de la Punta San Sebastián frente a la aduana donde deben en adelante practicarse las cargas y descargas de todo buque... permitiendo que los que hayan concluido el desalije y requisa, se conduzcan a la rada o Puerto que más le acomode". $A G P C, C N M G$, tomo I.

${ }^{23}$ Martin de Moussy señala que los grandes vapores de guerra y corbetas de la flota anglo-francesa que remontaron el Paraná con el convoy de buques mercantes que se dirigían a Corrientes en 1846 debieron elegir los meses de enero y febrero para esa expedición. José Carlos Chiaramonte ha examinado el porte de los buques que arribaban al puerto de Corrientes en base al impuesto de las patentes. El monto de este derecho se fijaba de acuerdo con una escala de tonelaje. Como ejemplo señala que en 1831 se pagaron 160 patentes. Del total, 13 patentes se otorgaron por buques de 86 toneladas o más. Asimismo de la comparación entre la cantidad de naves registradas y el monto de lo recaudado entre 1827 y 1840 concluye que a partir de la década de 1830 se aprecia un aumento de tonelaje medio de las embarcaciones. Chiaramonte, 1991; 78-81.

${ }^{24}$ Un testimonio sobre un accidente de este tipo se encuentra en la demanda de Domingo Latorre y Eugenio Barrios contra Antonio Pinedo, maestre y sobrecargo de la Balandra Liguria, $A G P C$, Judiciales, tomo 
para mejorar las condiciones de funcionamiento en el puerto principal. Así, durante el segundo gobierno de Pedro Ferré (1830-1833), con el fin despejar el área de descarga, se dispuso la expropiación de las casas particulares ubicadas en la costa hasta una cuadra al este de la aduana (ley del 19 de julio de 1832). ${ }^{25}$ Por su parte, el gobernador Joaquín Madariaga a fines de 1846 propuso un plan tareas que incluía el establecimiento de boyas, la construcción de dos muelles y de un dique "impidiendo los perjuicios que las corrientes causaban" así como la formación de un paseo de alamedas "que servirá de adorno y de desahogo a la población”. De este proyecto general sólo se concretó la realización de un muelle de piedra. La construcción, aunque modesta, constituía una obra excepcional para la época en la zona del Litoral. ${ }^{26}$

Entre la ciudad de Corrientes y la desembocadura del río Santa Lucía la costa del Paraná presenta alternativamente zonas de terrenos elevados y áreas bajas y pantanosas. En los puntos más sobresalientes se ubicaron las poblaciones de Empedrado y Bella Vista. Esta última se hallaba situada sobre una barranca arenosa que se elevaba unos treinta metros de la costa. No había inconvenientes para el acceso de los buques pero no era sencillo superar la altura para transportar los productos. En el informe ya mencionado de 1853 se indicaba que "lo que necesita [la localidad] es una bajada amplia y cómoda, y es de precisión hacer una obra sólida que no esté sujeta a la destrucción que continuamente causan las lluvias". ${ }^{27}$

En el sector de la costa comprendido entre el río Santa Lucía y el Guayquiraró las condiciones son mucho menos favorables para la actividad portuaria. La costa es generalmente baja e inundable. Como los terrenos más favorables para las poblaciones se hallan alejados del cauce principal los puertos se ubicaron a orillas de canales secundarios. El puerto de Goya se formó sobre el riacho del mismo nombre, definido entre la costa y una extensa isla. Por su parte, el puerto de Esquina se comunicaba con el curso principal por los brazos del delta que forma el río Corrientes en su desembocadura con el Paraná. Las desfavorables condiciones del sitio creaban serias dificultades para el acceso de las embarcaciones. En este aspecto un problema grave se planteó en Goya a partir de la década de 1840 por la obstrucción paulatina de la boca norte del riacho debido a la acumulación de sedimentos. El obstáculo limitaba el ingreso directo al puerto de los buques de mayor calado como las goletas y bergantines y a veces interrumpía la navegación por completo. Se señalaba en el informe de 1853 que "El Puerto de la ciudad de Goya es malísimo cuando está el Paraná bajo... y solamente es accesible a las embarcaciones... en las crecientes periódicas". ${ }^{28}$ Debido a las dificultades que

232, f. 180-187. Un suceso similar se describe en la obra de Mackinnon, 1957, pp. 116-118.

${ }^{25} R O$, tomo III, $1831-1837$, p. 98.

${ }^{26}$ Mensajes del gobernador Joaquín Madariaga, 21 de octubre de 1846 y 6 de mayo de 1847; AGPC, Libro de Actas de la Cámara de Diputados, tomo I. En la edición del 22 de junio de 1855 del diario El Comercio, se indica "hemos visto que la muralla de ésta principia a desmoronarse; ahora que su compostura es fácil y de poco costo llamamos la atención de quien corresponde".

${ }^{27}$ Razón que se da al Ministerio... AGPC, EA, leg. 117.

${ }^{28}$ Razón que se da al Ministerio... AGPC, EA, leg. 117. 
producía a la actividad comercial se realizaron algunos intentos para la reapertura del canal aunque sin resultados. ${ }^{29}$

En la década de 1850 la navegación de los ríos experimentó una transformación fundamental con la aparición de los primeros buques de vapor. Si bien hasta que concluyó la administración correntina el comercio fluvial se desarrolló sobre todo con las embarcaciones de vela los avances técnicos pusieron de manifiesto las limitaciones de los desembarcaderos naturales y la necesidad de mayores inversiones en el equipamiento portuario. Esta labor quedó a cargo del gobierno nacional que comenzó a introducir las primeras mejoras en los decenios de 1860 y 1870 (Pérez, 1989).

A diferencia de lo que ocurría en el área del Paraná, la vinculación fluvial del sector correntino del río Uruguay con las poblaciones situadas al sur enfrentaba un serio obstáculo por los afloramientos rocosos situados cerca de las localidades de Salto y Concordia. La navegación río abajo sólo era posible en los períodos de grandes crecientes lo que contribuyó al aislamiento de la zona. Los vínculos comerciales más sólidos se establecieron con las poblaciones vecinas de la ribera oriental. Paso de los Libres concentraba el comercio con el Brasil. Como otros puertos de la zona no se ubicaba sobre el río principal sino sobre un arroyo, el Yatai, que desemboca en el Uruguay. De esta forma se buscaba limitar los perjuicios que producían las rápidas crecientes de este río. El arroyo era navegable y permitía el ingreso de goletas todo el año. El pasaje de hacienda y otros productos hacia la vecina orilla se efectuaba en botes planos y en canoas construidos en el lugar (Moussy, 1860; III, pp.43 y 144).

La administración de las aduanas en los puertos habilitados constituía una cuestión de vital importancia para el Estado provincial ya que regularmente entre el 60\% y el 70\% de los ingresos fiscales provenía de la recaudación de los impuestos al comercio exterior. El sistema quedó organizado a partir de un conjunto de disposiciones adoptadas durante el primer gobierno de Pedro Ferré (1824-1828). ${ }^{30}$ Las autoridades principales de la administración fiscal residían en la ciudad de Corrientes. El funcionario de mayor jerarquía, inicialmente denominado Ministro de Hacienda, a partir enero de 1825 pasó

\footnotetext{
${ }^{29}$ En julio de 1841el vecindario designó una comisión para reconocer el riacho y proponer soluciones. La misma determinó que con la destrucción de raigones y "haciendo una pequeña excavación" se daría nuevamente entrada a las aguas. Posteriormente en 1847, el gobernador Madariaga informaba en su mensaje al Congreso sobre la apertura de un canal en el riacho. Una empresa más ambiciosa se llevó adelante en los inicios del gobierno de Juan Pujol durante los años 1852 y 1853 . La misma, ejecutada por el ingeniero Nicolás Grondona, buscaba encauzar el riacho mediante el cierre de bocas secundarias y la apertura de un canal "de modo que entre una cantidad de agua bastante para dar curso a cualquier buque, sin comprometer la vida y propiedad de las personas". Sin embargo, "después de la inversión de algunos miles" el gobernador se persuadió de que el costo de la obra excedía las posibilidades de la provincia. AGPC, EA, leg. 63; Mensaje del gobernador Joaquín Madariaga (6 de mayo de 1847), AGPC, Libro de Actas de la Cámara de Diputados, tomo I; "Memoria escrita por el ingeniero Nicolás Grondona en referencia a las obras del riacho de Goya", Corrientes en la Organización Nacional, tomo 3, pp. 16-25; Mensaje del gobernador Juan Pujol (4 de diciembre de 1859), RO, tomo VIII, p. 434.

${ }^{30}$ Las disposiciones fundamentales fueron: Ley de arancel y reglamento general de aduana (26 de enero de 1825); Decreto reglamentario de las operaciones portuarias y de policía de puerto (29 de enero 1825); Decreto reglamentario de las operaciones de contaduría fiscal y aduana (21 de septiembre de 1825); $R O$, tomo I, pp. 389-393 y 411-420.
} 
a llamarse Colector General. A él estaban subordinados todos los empleados vinculados con el manejo de los fondos públicos. Desde ese año se designó también un Contador Interventor quien, entre otras tareas, debía efectuar el reconocimiento y el aforo de los artículos para la percepción de los derechos. Estos dos funcionarios contaban con la colaboración de un pequeño número de dependientes. Tanto los empleados jerárquicos como los subordinados percibían un salario regular y duraban muchos años en sus funciones. La oficina de la hacienda en la ciudad de Corrientes constituía así el único sector de la administración civil donde se formó un núcleo de agentes especializados. ${ }^{31}$ En los otros puertos la percepción de los impuestos estaba a cargo de los receptores de alcabala. En un principio estos empleados recibían un porcentaje de los ingresos pero a partir de las reformas de Ferré los receptores de los centros de mayor actividad (Goya, Bella Vista, Paso de los Libres) comenzaron también a percibir un sueldo mensual. ${ }^{32}$ En general, la rotación de funcionarios en los puertos subordinados era mayor que en la capital en gran medida porque no siempre era fácil encontrar empleados idóneos. En lo que respecta a la seguridad, desde la etapa colonial funcionó en la ciudad de Corrientes una Capitanía de puertos integrada por un reducido piquete. Tras las reformas de Ferré también en Goya y Bella Vista se separaron las funciones de la receptoría y de la capitanía. En los otros la vigilancia dependía del receptor con ayuda del comandante de la plaza.

Todos los esfuerzos por perfeccionar el aparato de recaudación se vieron acompañados por inversiones en edificios públicos. Las construcciones más importantes, por supuesto, se realizaron en la ciudad capital. La casa de gobierno y las diferentes oficinas públicas se instalaron en el antiguo colegio de los jesuitas. Durante el primer gobierno de Pedro Ferré este edificio fue totalmente remodelado y se construyeron las oficinas de la aduana y los depósitos donde se guardaban los artículos desembarcados antes de que fueran retirados tras el pago de los impuestos. Asimismo se edificó una casilla de resguardo en la punta San Sebastián para controlar el movimiento portuario. ${ }^{33}$ En los pueblos del interior a lo largo de las décadas de 1820 y 1830 se fueron construyendo los edificios de las comandancias militares a las que se anexaba la oficina de la receptoría.

\footnotetext{
${ }^{31}$ En 1830, los empleados auxiliares de la colecturía eran tres, en 1853, en el momento previo de la transferencia de las aduanas a la jurisdicción nacional, llegaban a siete. Desempeñaron el cargo de Colector General: Manuel Serapio Mantilla y Ríos (1821-1825), Sebastián Almirón (1825-1835) y Manuel Serapio Mantilla (1835-1855). Los dos primeros continuaron en el puesto hasta su fallecimiento, el tercero se mantuvo hasta que se produjo la nacionalización de las aduanas. Asimismo en el informe de 1853 sobre las aduanas de la provincia se indica que el Contador Interventor llevaba diecisiete años en funciones y los empleados auxiliares entre cinco y siete años. Razón que se da al Ministerio... AGPC, EA, leg. 117.

32 Desde la etapa colonial los receptores gozaban de un ingreso del $6 \%$ de la recaudación pero a partir de una orden del gobernador Juan Bautista Méndez, del 5 de marzo de 1818, la retribución aumentó al 10\%, AGPC, Correspondencia Oficial, leg. 8, f. 190.

33 Gutiérrez y Sánchez Negrette, 1988; 122-128. En el informe de 1853 se afirma que "En esta capital, hay un edificio público que por su local y amplitud, presenta comodidad para el servicio de la aduana a cuyo objeto sirve actualmente". Razón que se da al Ministerio... AGPC, EA,leg. 117.
} 
Goya y Bella Vista contaron con edificios exclusivos para la receptoría y la capitanía de puerto. ${ }^{34}$

\section{Evolución general del comercio exterior de la provincia}

Como resultado de la expansión ganadera de la segunda mitad del siglo XVIII el comercio de Corrientes con otros distritos creció en forma sostenida. Desde 1790 en adelante la exportación de cueros vacunos y equinos "secos" (sin curtir) constituyó la base del tráfico exterior de la comarca. También se extraían, cueros curtidos, animales en pie, otros subproductos pecuarios, diversos frutos agrícolas, elaboraciones textiles y maderas (Maeder, 1981; Wentzel, 1988). El afianzamiento de los vínculos mercantiles implicó también la entrada regular de productos importados, un cambio fundamental para una comarca que había vivido en el aislamiento. Sin embargo, debido a las restricciones que imponía el sistema colonial español la oferta de bienes era limitada y cara por lo que el valor de las importaciones creció mucho más lentamente que el de las exportaciones. $^{35}$

Durante la etapa inicial del período independiente, entre 1810 y 1821, las luchas que se desarrollaron en el Litoral perjudicaron el comercio de los ríos. El tráfico de Corrientes experimentó fuertes altibajos por la clausura intermitente de las vías fluviales. La inestabilidad política y social desorganizó las actividades productivas por lo que las exportaciones de cueros se sostuvieron en base al consumo sin control de las existencias pecuarias (Robertson, 1950; Salvatore, 1995; Wentzel, 1988). En el caso de las importaciones, la apertura al comercio libre amplió el flujo de efectos en toda el área rioplatense, pero en Corrientes el impacto se vio limitado por los fuertes recargos que impuso la política aduanera y por la crisis económica general.

\footnotetext{
${ }^{34}$ Razón que se da al Ministerio... AGPC, EA, leg. 117; "Las casas de Aduana y Resguardo que se han edificado en Bella Vista, como uno de los puertos habilitados de la provincia, a más de corresponder cumplidamente a los objetos de su destino, sirven de ornato al pueblo", Mensaje de Pedro Ferré (8 de noviembre de 1833), $R O$, tomo III, 1831-1837, p. 205. Todavía en 1830 el edificio de la aduana de Goya se ubicaba en una casa alquilada. En su mensaje del 6 de diciembre de 1836, el gobernador Rafael Atienza afirmaba que "el plan de edificar gradualmente en la campaña, casas de seguridad, cuarteles y otras piezas para oficinas, ha producido los mejores resultados... En la villa de Goya un edificio de material cocido que comprende hasta el número de ocho piezas... está a punto de construirse" $R O$, tomo III, 1831-1837, p. 372.

35 En el período de 1805-1809 el valor promedio de las importaciones por el puerto de Corrientes fue de alrededor de 33.000 pesos, mientras que el de las exportaciones fue de 83.000 pesos. Debe destacarse que hubo fuertes variaciones anuales. $A G P C, E A$, leg. 1 .
} 


\section{Comercio de la provincia de Corrientes}

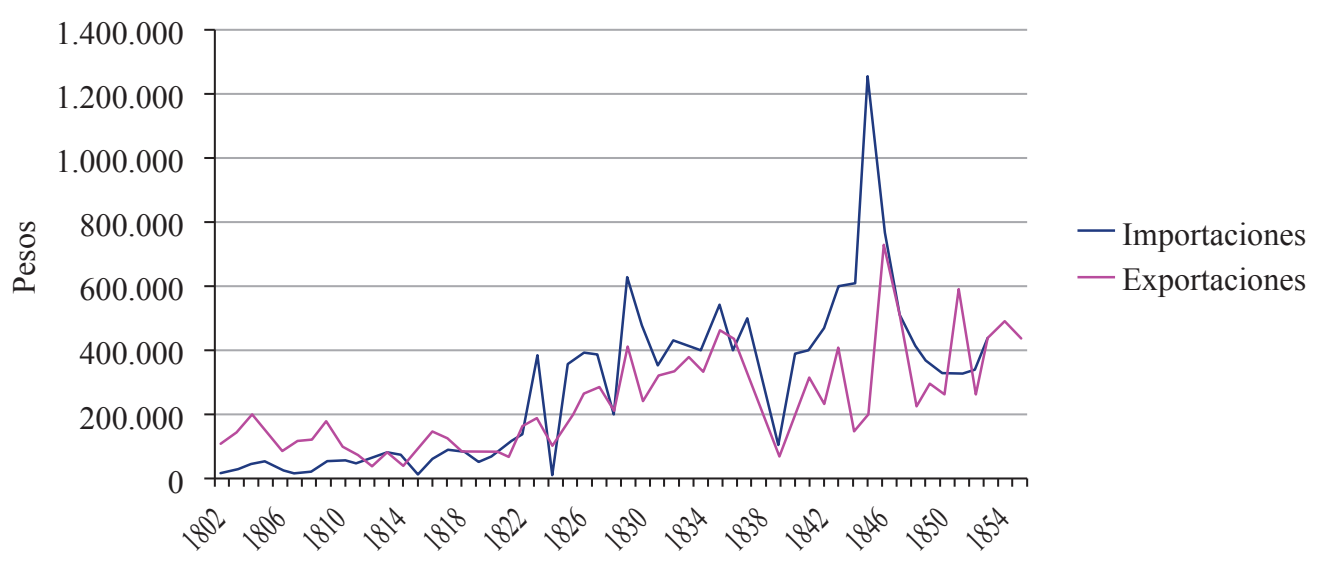

Concluidas las luchas se abrió un período sumamente favorable para el comercio correntino. La organización provincial iniciada en octubre de 1821 permitió el restablecimiento del orden interno y la recuperación de las actividades productivas. El lapso de 1822 a 1835 constituyó la etapa más próspera del tráfico fluvial en la primera mitad del siglo XIX. El valor de las exportaciones creció de manera sostenida. Durante la década de 1820 la disminución de la venta de cueros sin curtir que resultó de la crisis ganadera en la etapa anterior fue ampliamente compensada por el aumento de las exportaciones de suelas, de tabaco y otros productos agrícolas, de maderas y de frutos silvestres. A fines del decenio la ganadería ya se había recuperado y las exportaciones pecuarias volvieron a aumentar. También Corrientes pudo beneficiarse como intermediaria de la venta de yerba paraguaya en los momentos en que el dictador Gaspar Rodríguez de Francia autorizaba este tráfico (Chiaramonte, 1991; Whigham, 2009; 7784). Paralelamente con el crecimiento de las exportaciones, tuvo lugar un avance aún más acelerado de las importaciones, favorecido por una política de apertura comercial. El flujo extraordinario de efectos de ultramar produjo un déficit permanente en la balanza comercial que preocupó a las autoridades de la provincia. Paulatinamente se recurrió a medidas restrictivas que culminaron en un conjunto de leyes proteccionistas en enero de 1831. Como resultado de las mismas el volumen de las importaciones durante la década de 1830 tendió a estabilizarse en los niveles alcanzados hasta ese momento.

La etapa más favorable para el comercio exterior de la provincia concluyó a mediados de la década de 1830. Comenzaron a manifestarse dificultades en algunas de las producciones más importantes como los cueros curtidos y el tabaco. La crisis se agravó con el bloqueo francés al puerto de Buenos Aires y luego con el inicio de las hostilidades contra el gobierno de Juan Manuel de Rosas. El lapso que se extiende de 1838 hasta 1845 constituyó un período de retroceso para la economía provincial. En esa etapa, salvo breves momentos, se interrumpió la vinculación con Buenos Aires. El 
tráfico se orientó hacia Montevideo, pero el acceso a esta plaza por el Paraná estaba sujeto a fuertes riesgos por la acción de los buques de la Confederación. En algunos momentos la vía fluvial quedó clausurada por completo para el comercio correntino. Para superar estas dificultades se incrementó el intercambio con Paraguay y Brasil y se buscaron canales alternativos por el río Uruguay. La prolongación del estado de guerra durante casi diez años produjo la caída de la actividad agrícola y forestal agravada por la apertura del comercio con el Paraguay que representó el ingreso masivo de frutos que competían con la producción local. Asimismo las incursiones de las fuerzas enemigas que saqueaban los recursos del terreno perjudicaron especialmente a las áreas ganaderas del sur. La evolución de las exportaciones, condicionada por las luchas, tuvo grandes fluctuaciones pero, en conjunto, las remesas sufrieron una fuerte reducción. Las importaciones experimentaron menos alteraciones y aún tendieron hacia el crecimiento. Esto se debió a la anulación de las medidas proteccionistas, a la fuerte demanda de bienes para el sostenimiento de la lucha y a la entrada forzosa de cargamentos de buques enemigos.

La etapa más crítica para el comercio por el Paraná concluyó con el arribo de una flota anglo-francesa a la capital correntina en febrero de 1846. La llegada del convoy levantó el bloqueo rosista y fue el primer paso hacia una reanudación del tráfico regular. A fines de 1847 el restablecimiento de la paz interna y de la vinculación con Buenos Aires crearon las condiciones para la recuperación económica. La misma, sin embargo, avanzó lentamente. Crecieron de manera sostenida las exportaciones pero este incremento se vio contrarrestado por una baja de los precios locales y la crisis definitiva de la producción de cueros curtidos y de tabaco. Por su parte, las importaciones tampoco aumentaron porque el gobierno restableció las medidas proteccionistas entre 1848 y 1851. Una clara tendencia hacia el crecimiento se definió recién en los primeros años de la década de 1850, particularmente tras la caída de Rosas. Esta nueva coyuntura favorable era impulsada por la supresión a las restricciones del comercio y una fuerte recuperación de los precios de los frutos exportables.

\section{Actividad portuaria y participación regional en el comercio exterior}

Dentro de este panorama la participación en el comercio de las diversas regiones de la provincia experimentó algunas variaciones pero en general mantuvo una gran estabilidad durante el período. 
Cuadro $\mathbf{n}^{0}$ 1. Participación de los puertos en valor total de las exportaciones ( $\%$ del total)

\begin{tabular}{cccccccccccc} 
Periodo & $\mathbf{1}$ & $\mathbf{2}$ & $\mathbf{3}$ & $\mathbf{4}$ & $\mathbf{5}$ & $\mathbf{6}$ & $\mathbf{7 -}$ & $\mathbf{8}$ & $\mathbf{9}$ & $\mathbf{1 0}$ & Total (pesos) \\
\hline $1805-1809$ & 61 & - & - & 39 & & - & - & - & - & - & $\mathbf{6 7 6 . 4 4 5}$ \\
\hline $1816-1820$ & 48,6 & - & - & 49,2 & 2,2 & - & - & - & - & - & $\mathbf{5 1 1 . 0 4 3}$ \\
\hline $1821-1825$ & 63,9 & 0,8 & - & 30,9 & 2,7 & 1,6 & - & - & - & 0,1 & $\mathbf{6 9 5 . 7 2 0}$ \\
\hline $1826-1830$ & 67 & 4,8 & - & 23,1 & 2,4 & 2,3 & - & - & - & 0,4 & $\mathbf{1 . 0 2 0 . 8 6 8}$ \\
\hline $1831-1835$ & 61,5 & 6,9 & - & 22,9 & 6 & 2,7 & - & - & - & - & $\mathbf{1 . 6 7 0 . 4 6 8}$ \\
\hline $1836-1840$ & 55,3 & 3,4 & - & 35,5 & 4 & 1,7 & - & - & - & - & $\mathbf{1 . 1 5 7 . 9 5 2}$ \\
\hline $1841-1845$ & 48,4 & 2,5 & - & 19,9 & - & 5,2 & 9,1 & 0,9 & 13,6 & 0,4 & $\mathbf{1 . 2 7 1 . 1 9 4}$ \\
\hline $1846-1850$ & 68,3 & 2,6 & 1 & 20 & 0,4 & 0,7 & 3,3 & 0,4 & 3,3 & - & $\mathbf{2 . 0 6 7 . 7 8 6}$ \\
\hline $1851-1855$ & 56,5 & 11,4 & 3,9 & 17 & 1,4 & 5,1 & 4,4 & 0,3 & - & - & $\mathbf{2 . 2 1 0 . 9 7 9}$ \\
\hline $1: C 017$
\end{tabular}

1: Corrientes; 2: Bella Vista; 3: Empedrado; 4: Goya; 5: Esquina; 6: Curuzú Cuatiá; 7: La Cruz; 8: Paso de los Libres; 9: Santo Tomé; 10: Otros.

Cuadro n ${ }^{0}$ 2. Participación de los puertos en el valor total de las importaciones (\% del total)

\begin{tabular}{ccccccccccc} 
Período & $\mathbf{1}$ & $\mathbf{2}$ & $\mathbf{3}$ & $\mathbf{4}$ & $\mathbf{5}$ & $\mathbf{6}$ & $\mathbf{7}$ & $\mathbf{8}$ & $\begin{array}{c}\text { Total } \\
\text { (pesos) }\end{array}$ & $\begin{array}{c}\text { Promedio anual } \\
\text { (pesos) }\end{array}$ \\
\hline $1817-1820$ & 75,9 & - & 23,8 & 0,3 & - & - & - & - & $\mathbf{2 8 5 . 6 2 8}$ & $\mathbf{7 1 . 4 0 7}$ \\
\hline $1821-1825$ & 82,4 & - & 16,7 & 0,3 & 0,6 & - & - & - & $\mathbf{1 . 0 1 9 . 9 1 8}$ & $\mathbf{2 5 4 . 9 8 0}$ \\
\hline $1826-1830$ & 77,4 & 0,7 & 17,6 & 1,5 & 2,8 & - & - & - & $\mathbf{1 . 9 2 7 . 6 5 7}$ & $\mathbf{3 8 5 . 5 3 1}$ \\
\hline $1831-1835$ & 62,8 & 2,9 & 24,3 & 6,1 & 3,9 & - & - & - & $\mathbf{2 . 0 3 4 . 5 7 7}$ & $\mathbf{4 0 6 . 9 1 6}$ \\
\hline $1841-1845$ & 79 & 0,6 & 9,7 & - & 3 & 4,2 & 3,2 & 0,3 & $\mathbf{2 . 4 2 9 . 5 1 2}$ & $\mathbf{4 9 9 . 1 9 0}$ \\
\hline $1846-1850$ & 76,9 & 1,2 & 16,7 & - & 0,3 & 3,9 & 0,9 & 0,1 & $\mathbf{2 . 1 3 4 . 6 7 7}$ & $\mathbf{4 2 6 . 9 3 5}$ \\
\hline $1851-1853$ & 60,3 & 6,1 & 29,3 & 0,2 & 1,9 & 2,2 & - & - & $\mathbf{1 . 0 9 2 . 4 8 8}$ & $\mathbf{3 6 4 . 1 6 3}$ \\
\hline
\end{tabular}

1: Corrientes; 2: Bella Vista; 3: Goya; 4: Esquina; 5: Curuzú Cuatiá; 6: Paso de los Libres; 7: Santo Tomé; 8: Otros.

La región del noroeste correntino, el área más poblada y productiva, concentró la actividad mercantil a través del puerto de Corrientes ${ }^{36}$. Este centro constituía el punto más favorable para la comunicación fluvial con otras comarcas pero tenía una situación menos ventajosa en relación con el interior provincial por su posición excéntrica y las difíciles comunicaciones. Pese a los inconvenientes normalmente el valor del tráfico anual de esta plaza superaba al de los otros centros de la provincia en su conjunto. Este predominio era menos marcado en el caso de las exportaciones dado que los frutos locales, voluminosos y de bajo valor por unidad, se extraían en los puertos más cercanos a las zonas de producción. En el caso de las importaciones pesaban más las ventajas estratégicas de la capital. Las facilidades de acceso a los centros abastecedores de bienes

\footnotetext{
${ }^{36}$ A mediados del siglo XIX la región del noroeste concentraba el 46\% de la población (censo de 1857) y el $32 \%$ de las existencias ganaderas de la provincia calculadas, hacia 1854, en alrededor de 670.000 vacunos. En 1857 la ciudad de Corrientes tenía cerca de 9.000 habitantes y Bella Vista alrededor de un millar.
} 
importados, así como las posibilidades para el trasbordo y el almacenamiento hacían de esta plaza el principal lugar de depósito y distribución. Como se aprecia en el cuadro siguiente desde la capital se surtían comercios de Goya, Bella Vista, los de los pueblos interiores del noroeste y aún los de la zona sur y la costa del Uruguay. Asimismo en los períodos en que existía una vinculación con el Paraguay una parte de las importaciones que ingresaban por la ciudad se reexpedía a este país.

Cuadro no 3. Guías de tránsito de efectos expedidas en la ciudad de Corrientes para el interior de la provincia y Paraguay $\left(\mathrm{n}^{\circ}\right)$

\begin{tabular}{ccccccccc} 
& $\mathbf{1 8 2 6}$ & $\mathbf{1 8 2 9}$ & $\mathbf{1 8 3 1}$ & $\mathbf{1 8 3 2}$ & $\mathbf{1 8 4 2}$ & $\mathbf{1 8 4 3}$ & $\mathbf{1 8 4 8}$ & $\mathbf{1 8 4 9}$ \\
\hline Paraguay & 13 & 108 & 70 & 56 & 59 & 54 & 60 & 17 \\
\hline Goya & 18 & 40 & 29 & 37 & 46 & 25 & 40 & 33 \\
\hline Bella Vista & - & 2 & 5 & 2 & 21 & 5 & 42 & 16 \\
\hline Pueblos del Noroeste & 11 & 26 & 25 & 25 & 5 & 2 & 14 & 10 \\
\hline
\end{tabular}

Pueblos entre el Santa Lucía y

El Guayquiraró

\begin{tabular}{lllllll}
18 & 21 & 22 & 4 & 2 & 6 & 11 \\
\hline
\end{tabular}

Pueblos de la cuenca del Uruguay

Sin especificar

$-18$

\begin{tabular}{cccccccc}
1 & 8 & 10 & 10 & - & 2 & 4 & 11 \\
12 & 21 & 11 & 11 & - & - & - & - \\
\hline
\end{tabular}

Fuente: AGPC Toma de Razón de las guías Marítimas y Terrestres, que se despachan en la Colecturía de la ciudad de Corrientes. 1820-1849

El otro puerto de la zona noroeste, Bella Vista, era el punto de contacto con el exterior del área agrícola y ganadera que comprendía el departamento de ese nombre y una amplia franja donde se levantaban las localidades de Saladas, Mburucuyá, Caá Catí y San Roque (De Moussy, 1860;137-138).

En lo que se refiere a las exportaciones, al finalizar la etapa colonial el puerto de Corrientes canalizaba alrededor del $60 \%$ del valor total de las remesas. Esta proporción se redujo durante la fase inicial del período independiente por el fuerte crecimiento de las salidas de cueros por Goya y Esquina. Restablecido el orden interno y el tráfico regular, durante la década de 1820 y hasta mediados de la siguiente se acentuó el predominio del puerto de la capital por el crecimiento de la producción agrícola y artesanal del noroeste y la crisis de la zona ganadera del sur. En este lapso, como se ha visto, se habilitó el puerto de Bella Vista que se afianzó rápidamente como centro de exportación. Durante la crisis bélica que se abrió a fines de la década de 1830 cayeron las exportaciones agrícolas y forestales y se estancaron las ganaderas. Asimismo gran parte del intercambio se canalizó por los puertos de la zona del Uruguay. El valor total de las remesas en el puerto de Corrientes durante el lapso 1836-1840 disminuyó en un $40 \%$ en relación con el del lustro anterior, mientras que en Bella Vista la reducción fue casi del 70\%. En el quinquenio siguiente el monto de las exportaciones fue similar pero aproximadamente el $27 \%$ estaba integrado por productos del Paraguay. De esta forma, la participación de los puertos del noroeste en el comercio de exportación se redujo. Con la finalización de la lucha contra Rosas volvió a crecer el aporte de la zona. Luego de la supresión del bloqueo durante los años 1846 y 1847 tuvo lugar un 
aumento extraordinario de la actividad del puerto de Corrientes por la salida de los frutos acumulados. Cuando se regularizó el tráfico el valor de las exportaciones tendió a estabilizarse. En la primera mitad de la década de 1850 la participación relativa de Corrientes disminuyó algo porque una buena proporción del tráfico se desvió hacia los puertos de Bella Vista y Empedrado. La actividad de la primera creció con fuerza ya que el valor de las exportaciones fue casi cinco veces superior al del lustro anterior.

En cuanto a las importaciones el predominio de la ciudad de Corrientes sobre el resto de la provincia fue aún mayor. Durante la década de 1820 concentró alrededor del $80 \%$ del total de las entradas. En el decenio de 1830 el impacto de las medidas proteccionistas se hizo sentir con fuerza en el principal centro de consumo. Las importaciones por el puerto de Corrientes se mantuvieron más o menos estancadas, mientras que crecían las de otros centros. En contraste, en el crítico período de la lucha contra Rosas, pese a las restricciones, el flujo de efectos importados no experimentó caídas pronunciadas. Fue marcada la preeminencia del puerto de Corrientes sobre el resto de la provincia por su papel de escala obligada en el tráfico con el Paraguay. ${ }^{37} \mathrm{La}$ fuerte concentración de la entrada de bienes en el puerto de la capital se mantuvo hasta fines de la década de 1840. A principios del decenio siguiente, sin embargo, tuvo lugar una paulatina caída de la participación proporcional del puerto que reflejaba sobre todo la recuperación de las otras plazas mercantiles de la provincia.

La región del sur del río Santa Lucía durante la última etapa del período colonial había constituido el área más dinámica del desarrollo ganadero provincial. Sin embargo, en la primera mitad del siglo XIX su crecimiento, muy afectado por las crisis bélicas, fue más lento y fluctuante. Las exportaciones se concentraban en el puerto de Goya. $\mathrm{Su}$ área de influencia abarcaba la vasta zona ganadera del sur de la provincia, desde el río Santa Lucía hasta la costa del Uruguay. ${ }^{38}$ Sin embargo, a mediados del siglo XIX su actividad comercial se hallaba amenazada por las dificultades de su puerto y la creciente competencia de la localidad entrerriana de Concordia en los departamentos del sur. ${ }^{39}$ Esquina, el otro puerto del sur de la provincia, era cabecera de un espacio más reducido,

\footnotetext{
${ }^{37}$ Durante los años 1844 y 1845 el bloqueo del Paraná produjo una caída de las importaciones regulares, pero hubo un ingreso extraordinario de efectos por el puerto de Corrientes como resultado de la captura (octubre de 1844) de una flota de buques mercantes que, con bandera de Buenos Aires, se dirigía hacia el Paraguay. Gran parte del cargamento fue embargado y utilizado para las necesidades del ejército.

${ }^{38}$ El área de influencia comprendía unos $36.000 \mathrm{Km} 2$ y a mediados del siglo XIX reunía el $35 \%$ de la población (1857) y el 60\% de las existencias ganaderas (1854). En 1857 Goya contaba con unos 1.800 habitantes y Esquina con alrededor de 400.

${ }^{39}$ En una nota publicada en el diario El Comercio (26 de agosto de 1855) se señalaba que "La Corriente Comercial que mantenía el movimiento mercantil en esta parte de la costa del Paraná, ha emigrado a la del Uruguay adonde van a proveerse los Departamentos de Restauración [Paso de los Libres], Curuzú Cuatiá y Mercedes que antes lo hacían en este punto. Queda pues hoy este mercado concentrado a llenar las necesidades del Departamento". Asimismo, un cronista de La Opinión ante la visible prosperidad de Bella Vista pronosticaba (7 de junio de 1857) que la plaza estaba llamada a "un inmenso desarrollo" y a "atraer con el tiempo todas las transacciones comerciales que hasta hoy han hecho esos diversos departamentos [San Roque, Saladas y Caá Cati] con la ciudad de Goya, que por causa de la dificultad de sus comunicaciones con el Paraná pierde cada día su importancia".
} 
una rinconada delimitada por el Paraná al oeste, el Guayquiraró al sur y al este una zona deprimida e inundable que la separaba de las lomadas de la región del Paiubre.

A fines de la etapa colonial ambos centros participaban con aproximadamente el $40 \%$ del valor de las remesas. Iniciado el movimiento independiente las exportaciones provinciales tendieron a desplazarse hacia estos puertos. Así en el lapso de 1816 a 1820 las salidas por Goya fueron levemente superiores a las de Corrientes. Pero, como se ha dicho, el crecimiento tenía un corto alcance pues se sustentaba en una destrucción de la riqueza pecuaria. La crisis ganadera se hizo sentir en el decenio de 1820 y produjo una fuerte caída de la región del sur. En valores absolutos las salidas por el puerto de Goya fueron menores en el quinquenio 1821-1825 que en el lustro anterior. Recién en la segunda mitad de la década de 1830 las exportaciones por Goya experimentaron un crecimiento sostenido, y en 1837 alcanzaron el valor más alto de la década. En lo que respecta a Esquina, pese a su reducida participación en el conjunto, se debe destacar el dinamismo comercial de la plaza en ese lapso. De esta forma en el quinquenio de 1836-1840 la participación de la región del sur en el total provincial llegó nuevamente a cerca del $40 \%$. Sin embargo durante el conflicto contra Rosas la inseguridad y las incursiones enemigas pronto frenaron la recuperación que se insinuaba. Las invasiones produjeron el abandono de Esquina que cesó de funcionar en 1840. Así en el quinquenio de 1841-1845 el valor total de las remesas de la región constituyó menos del 20\% de total provincial.

En lo que respecta a las importaciones, aunque el volumen de las mismas en Goya siempre fue muy inferior al de Corrientes, también resultó menos afectado por las políticas comerciales que se aplicaron en el período. Durante la década de 1820 la liberación mercantil se hizo sentir en forma limitada y tardía, mientras que en el decenio de 1830, el valor de las introducciones por esta plaza no cesó de crecer pese a las medidas proteccionistas. En la década siguiente las importaciones se paralizaron como resultado de la crisis bélica.

Restablecida la paz, la actividad de los puertos del sur experimentó sólo una moderada recuperación. Esquina reanudó sus operaciones y también creció el intercambio por el puerto de Goya. Sin embargo, a principios de la década de 1850 el valor de las exportaciones en ambos centros todavía no alcanzaba los montos de los mejores años del decenio de 1830. Como se ha dicho, en el caso de Goya, su actividad tuvo dificultades por el cierre del canal de acceso al puerto y la competencia de Concordia.

Hasta el inicio de la lucha contra Rosas el comercio de los puntos habilitados en la zona del Uruguay representó poco dentro del conjunto y experimentó variaciones motivadas por los conflictos fronterizos. En los años de mayor actividad (1829 y 1835) el monto de las exportaciones por Curuzú Cuatiá alcanzó a cerca del 5\% del total provincial, en tanto que durante $1826-1828$ no hubo remesas debido a la guerra con el Brasil. Hay que tener en cuenta, no obstante, que el comercio registrado era solo una parte del total debido al activo contrabando que existía en esa zona poco poblada y difícil de controlar. La salida irregular de hacienda, sobre todo de caballos, fue, al parecer, bastante considerable. ${ }^{40}$ En la década de 1840 creció la importancia del Uruguay como

${ }^{40}$ El gobierno provincial en la década de 1830 dictó numerosas disposiciones para reprimir el comercio 
vía alternativa por las dificultades del comercio por el río Paraná. La reorientación del tráfico se hizo sentir sobre todo en las exportaciones. En conjunto, el valor de las remesas por las localidades de la costa del Uruguay durante la primera mitad de la década de 1840 alcanzó al 29\% del total provincial y alrededor del 11\% el de las importaciones. ${ }^{41}$ A fines de ese decenio y principios del siguiente se produjo una caída temporal por la reapertura del Paraná y los conflictos con los estados vecinos. Santo Tomé fue destruido por las fuerzas paraguayas en1849 y la ruptura de la Confederación con el Brasil, en 1850, interrumpió momentáneamente la actividad de Paso de los Libres. Una vez que se estabilizó la situación política el comercio se reanudó con fuerza. Curuzú Cuatiá se vinculó estrechamente con Concordia hacia donde se exportaban frutos pecuarios y animales en pie a cambio de efectos de ultramar. El valor medio de las exportaciones anuales por Curuzú Cuatiá entre 1852 y 1855 duplicaba el de los mejores años de la década de 1830. Por su parte, el tráfico de Paso de los Libres con Brasil alcanzó montos similares a los de la etapa del período bélico, cuando era una de las pocas vías de intercambio de la provincia. De todas formas a mediados de la década de 1850 la magnitud del comercio por los puntos habilitados en la zona del Uruguay estaba todavía lejos de los valores de la zona del Paraná. En el quinquenio de 1851-1855 los puertos del este de la provincia participaban con un $10 \%$ del valor total de las exportaciones y un $4 \%$ del de las importaciones.

\section{El comercio de frutos}

De manera similar a las otras zonas del Litoral el comercio de Corrientes se fundaba en la exportación de cueros y otros frutos ganaderos pero, a diferencia de aquéllas, contaba con una mayor variedad de producciones regionales.

Cuadro $\mathbf{N}^{\circ}$ 4. Composición de las exportaciones de la provincia de Corrientes (\% del total)

\begin{tabular}{ccccccccccc} 
Período & $\mathbf{1}$ & $\mathbf{2}$ & $\mathbf{3}$ & $\mathbf{4}$ & $\mathbf{5}$ & $\mathbf{6}$ & $\mathbf{7}$ & $\mathbf{8}$ & $\mathbf{9}$ & Total (pesos) \\
\hline $1816-1820$ & 79,2 & 7,9 & 4,4 & - & 0,4 & 0,2 & 6,2 & 1,3 & 0,4 & $\mathbf{5 1 1 . 0 4 3}$ \\
\hline $1821-1825$ & 53,2 & 13,2 & 2,4 & 1,8 & 9,6 & 10 & 2,3 & 7,2 & 0,3 & $\mathbf{6 9 5 . 7 2 0}$ \\
\hline $1826-1830$ & 31,6 & 13 & 3,4 & 2,1 & 19 & 11,5 & 3,4 & 11,5 & 4,5 & $\mathbf{1 . 0 2 0 . 8 6 8}$ \\
\hline $1831-1835$ & 39,8 & 10,7 & 8,7 & 2,7 & 23,4 & 2,7 & 1,9 & 5,4 & 4,7 & $\mathbf{1 . 6 7 0 . 4 6 8}$ \\
\hline $1836-1840$ & 45,6 & 8,1 & 21,5 & 1,3 & 15,3 & 1,3 & 1 & 4,7 & 1,1 & $\mathbf{1 . 1 5 7 . 9 5 2}$ \\
\hline $1841-1845$ & 44,7 & 7,1 & 9 & 6,6 & 18,9 & 12,2 & 0,4 & 0,9 & 0,2 & $\mathbf{1 . 2 7 1 . 1 9 4}$ \\
\hline $1846-1850$ & 53,5 & 3,5 & 10,7 & 3,3 & 11 & 10,4 & 1,6 & 4,4 & 1,6 & $\mathbf{2 . 0 6 7 . 7 8 6}$ \\
\hline $1851-1855$ & 44,6 & 2,5 & 12 & 4 & 3,8 & 14,1 & 4,1 & 14,3 & 0,6 & $\mathbf{2 . 2 1 0 . 9 7 9}$ \\
\hline
\end{tabular}

1: cueros; 2: suelas; 3: otros subproductos ganaderos; 4: animales en pie; 5 : tabaco; 6: yerba; 7: productos agrícolas varios; 8: maderas; 9: otros.

ilegal debido a que se repetía "con escándalo, el sórdido manejo de los contrabandos". $R O$, tomo III, pp.343-345. El área comprendida entre el Miriñay y el Aguapey, con una superficie de unos 30.000 km2, reunía a mediados del siglo XIX el 6,7\% de la población y el 3\% de los vacunos.

${ }^{41}$ Estos porcentajes corresponden al agregado del quinquenio pero hay que tener en cuenta que hubo fuertes variaciones anuales. En 1844 y 1845, la participación en las exportaciones de los puertos del este provincial fue del $90 \%$ y del $76 \%$ respectivamente. Paso de los Libres y Santo Tomé fueron las localidades más activas del comercio exterior correntino durante esos años. 
En el área noroeste junto con la actividad ganadera prosperaban cultivos subtropicales similares a los del sur del Paraguay. Además, en la vecina región del Chaco existía una inmensa riqueza forestal que podía aprovecharse en las zonas ribereñas. Las comarcas del sur de la provincia, por su parte, con un clima más templado, se orientaban hacia la especialización ganadera. Asimismo, en determinados momentos, Corrientes participó como intermediaria en el comercio de la yerba y el tabaco paraguayos. Esta mayor diversidad de bienes ampliaba las posibilidades comerciales y permitió compensar las caídas en alguno de los rubros de exportación. Como contrapartida, la provincia no pudo aprovechar plenamente los beneficios resultantes de una especialización productiva. Experimentó de manera tardía y limitada las transformaciones de la ganadería rioplatense y los productos agrícolas y sus elaboraciones debían enfrentar la concurrencia de frutos similares del Brasil o del Paraguay. La participación de los diferentes productos en las exportaciones varió de acuerdo con las condiciones del comercio. En los momentos de mayor incertidumbre, como en los períodos de 1810-1821 y 1840-1847 el tráfico de frutos tendía a especializarse en la venta de cueros, mientras que en los momentos de estabilidad, la composición de las remesas se diversificaba.

Dentro de este panorama general las salidas por el puerto de la ciudad de Corrientes no sólo superaban en volumen y valor a las de los otros centros habilitados sino que además incorporaban la mayor variedad de productos.

Cuadro $\mathbf{n}^{0}$ 5. Composición de las exportaciones del puerto de la ciudad de Corrientes (\% del total)

\begin{tabular}{ccccccccccc} 
Período & $\mathbf{1}$ & $\mathbf{2}$ & $\mathbf{3}$ & $\mathbf{4}$ & $\mathbf{5}$ & $\mathbf{6}$ & $\mathbf{7}$ & $\mathbf{8}$ & $\mathbf{9}$ & Total (pesos) \\
\hline $1816-1820$ & 62,3 & 16,1 & 24,8 & 0,4 & 0,6 & 12,3 & 2,6 & 0,3 & 0,2 & $\mathbf{2 4 8 . 3 2 2}$ \\
\hline $1821-1825$ & 35,8 & 21,6 & 2,3 & 13,1 & 12,2 & 3,6 & 10,1 & 0,2 & 1,1 & $\mathbf{4 4 4 . 6 4 0}$ \\
\hline $1826-1830$ & 17 & 20,1 & 3,2 & 23,8 & 15,3 & 4,2 & 13,3 & 2,7 & 0,3 & $\mathbf{6 8 4 . 3 1 0}$ \\
\hline $1831-1835$ & 28,3 & 17,3 & 5,5 & 31,3 & 3 & 2,4 & 8 & 3,9 & 0,3 & $\mathbf{1 . 0 2 6 . 9 5 4}$ \\
\hline $1836-1840$ & 36,7 & 14,5 & 16,4 & 21,7 & - & 1,3 & 8 & 1,3 & 0,1 & $\mathbf{6 4 0 . 1 4 1}$ \\
\hline $1841-1845$ & 30,8 & 2,1 & 7 & 22,9 & 22,6 & 0,1 & 0,6 & 0,3 & 3,6 & $\mathbf{6 1 5 . 1 6 3}$ \\
\hline $1846-1850$ & 46 & 6 & 7,7 & 16 & 13,5 & 2,5 & 7,8 & 0,3 & 0,2 & $\mathbf{1 . 4 1 2 . 3 3 1}$ \\
\hline $1851-1855$ & 46,5 & 4,5 & 10,6 & 3,5 & 14,2 & 2,5 & 17,4 & 0,6 & 0,4 & $\mathbf{1 . 2 4 9 . 6 8 0}$ \\
\hline
\end{tabular}

1: cueros; 2: suelas; 3: otros subproductos ganaderos; 4: tabaco; 5: yerba; 6: otros productos agrícolas; 7: maderas; 8: productos silvestres; 9: otros. 
Cuadro $N^{0}$ 6. Exportaciones por el puerto de Corrientes. Subproductos ganaderos

\begin{tabular}{ccccccccc} 
& \multicolumn{2}{c}{ Cueros } & \multicolumn{2}{c}{ Cueros curtidos } & \multicolumn{2}{c}{ Crin } & \multicolumn{2}{c}{ Grasa } \\
\hline Período & $\mathbf{N}^{\mathbf{0}}$ & $\begin{array}{c}\text { \% de la } \\
\text { provincia }\end{array}$ & $\mathbf{N}^{\mathbf{0}}$ & $\begin{array}{c}\text { \% de la } \\
\text { provincia }\end{array}$ & Arrobas & $\begin{array}{c}\text { \% de la } \\
\text { provincia }\end{array}$ & Arrobas ${ }^{\mathbf{1}}$ & $\begin{array}{c}\text { \% de la } \\
\text { Provincia }\end{array}$ \\
\hline $1816-20$ & 213.755 & $\mathbf{3 7}$ & 19.583 & $\mathbf{1 0 0}$ & 6851 & $\mathbf{4 4 , 6}$ & - & - \\
\hline $1821-25$ & 114.436 & $\mathbf{3 5 , 1}$ & 24.338 & $\mathbf{1 0 0}$ & 11.235 & $\mathbf{5 9 , 3}$ & - & - \\
\hline $1826-30$ & 55.031 & $\mathbf{3 6 , 7}$ & 27.661 & $\mathbf{9 9 , 9}$ & 10.514 & $\mathbf{5 5 , 9}$ & - & - \\
\hline $1831-35$ & 113.423 & $\mathbf{4 1 , 8}$ & 40.246 & $\mathbf{1 0 0}$ & 22.798 & $\mathbf{4 7 , 2}$ & 2.003 & $\mathbf{6 2 , 4}$ \\
\hline $1836-40$ & 101.682 & $\mathbf{4 2 , 4}$ & 23.878 & $\mathbf{9 9 , 2}$ & 22.020 & $\mathbf{4 2 , 2}$ & 6.362 & $\mathbf{3 6 , 5}$ \\
\hline $1841-45$ & 200.668 & $\mathbf{4 4 , 5}$ & 18.921 & $\mathbf{7 6 , 8}$ & 16.080 & $\mathbf{3 2 , 8}$ & 3.380 & $\mathbf{2 2 , 3}$ \\
\hline $1846-50$ & 699.263 & $\mathbf{6 2 , 1}$ & 25.260 & $\mathbf{9 7}$ & 59.277 & $\mathbf{5 3 , 4}$ & 320 & $\mathbf{2 , 5}$ \\
\hline $1851-55$ & 220.032 & $\mathbf{5 1 , 8}$ & 14.761 & $\mathbf{9 1 , 7}$ & 26.377 & $\mathbf{3 5 , 8}$ & 16.043 & $\mathbf{5 5 , 2}$ \\
\hline
\end{tabular}

La mayor parte de los cueros "secos" de la provincia se exportaban por los puertos de Corrientes y Goya. Hasta principios de la década de 1830 las cantidades extraídas por Goya superaban a las de Corrientes, en ese decenio las remesas tendieron a equilibrarse y a partir de la década de 1840 el puerto de la capital superó ampliamente a la localidad del sur. Por su parte, los cueros curtidos por su alto valor agregado constituyeron durante mucho tiempo uno de los artículos más importantes del comercio correntino. Esta contribución es más significativa si se tiene en cuenta que la misma resultaba de la actividad de un reducido número de curtiembres (ocho en los años más prósperos). La industria, iniciada hacia 1801, se concentraba en la capital, por lo tanto su puerto constituyó prácticamente el único centro de exportación. Desde mediados de la década de 1830 la actividad comenzó a experimentar dificultades por la caída de la demanda. Las luchas y la competencia de los productos de otras regiones aceleraron la decadencia de tal forma que hacia mediados del siglo XIX la participación de las suelas en el comercio exterior de la provincia era insignificante (Chiaramonte, 1991; 127-129). También por el puerto de Corrientes se extraía una buena parte de los cargamentos de crin, grasa, sebo, tasajo y otros subproductos pecuarios. El crecimiento de las extracciones fue notable desde la década de 1830 porque en las cercanías de la capital funcionó un saladero entre 1835 y 1838. Dos nuevos establecimientos volvieron a instalarse en la primera mitad de la década de $1850 .^{42}$

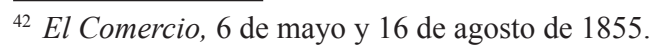


Cuadro $\mathbf{n}^{0}$ 7. Exportaciones por el puerto de Corrientes. Productos agrícolas y forestales

\begin{tabular}{ccccccccc} 
Período & \multicolumn{2}{c}{ Tabaco } & \multicolumn{2}{c}{ Yerba mate } & \multicolumn{2}{c}{ Naranjas } & \multicolumn{2}{c}{ Maderas } \\
\hline & Arrobas & $\begin{array}{c}\text { \% de la } \\
\text { provincia }\end{array}$ & Arrobas & $\begin{array}{c}\text { \% de la } \\
\text { provincia }\end{array}$ & $\mathbf{N}^{\mathbf{2}}$ & $\begin{array}{c}\text { \% de la } \\
\text { provincia }\end{array}$ & Varas $^{2}$ & $\begin{array}{c}\text { \% de la } \\
\text { provincia }\end{array}$ \\
\hline $1816-20$ & 481 & $\mathbf{1 0 0}$ & 726 & $\mathbf{1 0 0}$ & 288.053 & $\mathbf{1 0 0}$ & 6.389 & $\mathbf{9 0 , 1}$ \\
\hline $1821-25$ & 10.775 & $\mathbf{8 6 , 6}$ & 7.813 & $\mathbf{6 1 , 7}$ & 1.586 .650 & $\mathbf{9 4 , 7}$ & 80.020 & $\mathbf{9 8 , 2}$ \\
\hline $1826-30$ & 22.222 & $\mathbf{8 1 , 4}$ & 15.666 & $\mathbf{9 8 , 6}$ & 1.628 .770 & $\mathbf{7 2 , 4}$ & 189.078 & $\mathbf{8 6}$ \\
\hline $1831-35$ & 48.762 & $\mathbf{8 0}$ & 5.627 & $\mathbf{4 8 , 8}$ & 3.910 .371 & $\mathbf{8 8 , 6}$ & 180.858 & $\mathbf{9 5 , 5}$ \\
\hline $1836-40$ & 22.538 & $\mathbf{6 9 , 7}$ & 54 & $\mathbf{0 , 3}$ & 1.489 .000 & $\mathbf{6 3 , 1}$ & 142.524 & $\mathbf{9 7 , 4}$ \\
\hline $1841-45$ & 34.633 & $\mathbf{5 2 , 6}$ & 37.575 & $\mathbf{6 3 , 9}$ & - & - & 12.536 & $\mathbf{8 2 , 7}$ \\
\hline $1846-50$ & 105.088 & $\mathbf{9 4 , 8}$ & 148.817 & $\mathbf{9 2 , 2}$ & 3.722 .617 & $\mathbf{5 9 , 3}$ & 255.818 & $\mathbf{7 2}$ \\
\hline $1851-55$ & 22.416 & $\mathbf{6 4}$ & 55.860 & $\mathbf{8 5 , 7}$ & 8.991 .100 & $\mathbf{4 7 , 9}$ & 683.603 & $\mathbf{6 6 , 3}$ \\
\hline
\end{tabular}

Las exportaciones agrícolas y forestales también se concentraban en el puerto de Corrientes. De los productos agrícolas y sus elaboraciones el tabaco en rama y los cigarros constituían los artículos más valiosos del comercio. Las áreas productoras se ubicaban en la lomadas arenosas del interior de la zona noroeste, sobre todo en torno de Caá Catí, Mburucuyá y Saladas. Durante la etapa de mayor desarrollo de este cultivo, en el lapso de 1826 a 1835 , normalmente por la plaza se extraía cerca del $80 \%$ del volumen total de las exportaciones provinciales. Desde mediados de la década de 1830 la producción local comenzó a decaer posiblemente por la competencia de productos importados de Brasil y otras regiones. Junto con el tabaco se exportaba una amplia variedad de productos agrícolas y sus elaboraciones aunque su participación en las remesas fue relativamente modesta. Hasta principios de la década de 1820 el algodón fue el artículo más valioso, durante los decenios de 1820 y 1830 creció la producción de maní, miel de caña, aguardiente y naranjas. En la etapa de la lucha contra Rosas los productos agrícolas desaparecieron de las exportaciones. Con el retorno de la regularidad del intercambio, a fines de la década de 1840 , se produjo un auge extraordinario del cultivo del naranjo. En contraste, el tabaco y otras producciones no lograron recuperarse. Este hecho señalaba un paulatino desplazamiento del centro de la actividad agrícola desde las áreas del interior hacia la zona de la costa del Paraná (D’Orbigny, 1955; Moussy, 1860; 131). Desde el puerto de la capital también se extraía la mayor cantidad de maderas labradas y semilabradas de la provincia. Allí se concentraba la actividad de aserraderos, carpinterías y astilleros. En estos últimos se construyeron gran parte de los buques que realizaban la carrera del Paraná. El crecimiento de las exportaciones fue en gran medida consecuencia de los acuerdos celebrados por el gobierno de la provincia con los indios del Chaco que permitieron la explotación de los bosques ribereños de esa región. Como en el caso de la agricultura, la actividad declinó durante la etapa de la lucha contra Rosas, pero se recuperó con fuerza en los últimos años de la década de 1840 y principios de la de 1850. En ese lapso se habilitó el puerto de Empedrado que concentró una parte del tráfico de maderas que antes se efectuaba por la ciudad de Corrientes. ${ }^{43}$

\footnotetext{
43 "En el semestre corrido del presente año se han cargado en el Puerto del Señor [Empedrado], con el
} 
Como resultado de la vinculación que la provincia mantuvo con el Paraguay durante la etapa de aislamiento de esta república, en algunos períodos, el puerto de la capital fue un importante centro de depósito y tránsito de productos paraguayos hacia los mercados del sur. Entre 1827 y 1833 canalizó gran parte de las limitadas cantidades de yerba que Gaspar Rodríguez de Francia autorizaba a exportar por la ruta del Paraná. Tras una larga interrupción, motivada por el conflicto sobre Misiones, el comercio se reanudó con fuerza en 1841. La exportación de tabaco y cigarros paraguayos fue un rubro importante con volúmenes ampliamente superiores a los de la producción local. Asimismo la yerba del Paraguay constituyó un componente regular de las remesas. A estos artículos se sumaron una amplia variedad de frutos agrícolas y ganaderos. Este tráfico también se interrumpió en 1853 porque la intermediación correntina resultó superflua al regularizarse las relaciones entre el Paraguay y la Confederación. ${ }^{44}$

Cuadro $\mathbf{n}^{\circ}$ 8. Composición de las exportaciones por el puerto de Bella Vista (\% del total)

\begin{tabular}{|c|c|c|c|c|c|c|c|}
\hline Período & Cueros & $\begin{array}{c}\text { Subprod. } \\
\text { ganaderos }\end{array}$ & Tabaco & $\begin{array}{c}\text { Prods. } \\
\text { agrícolas }\end{array}$ & Maderas & otros & $\begin{array}{c}\text { Total en } \\
\text { pesos }\end{array}$ \\
\hline $1825-30$ & 58,7 & 3,9 & 21,4 & 5,3 & 10,2 & 0,5 & 54.592 \\
\hline $1831-35$ & 58,2 & 17,4 & 18,2 & 3 & 0,9 & 2,3 & 114.862 \\
\hline $1836-40$ & 47,4 & 33,8 & 11 & 6,1 & 1,3 & 0,4 & 39.936 \\
\hline $1841-45$ & 63,2 & 16,1 & 7,8 & 0,5 & 2 & 10,4 & 32.215 \\
\hline $1846-50$ & 69,4 & 14 & 2,4 & 7 & 5,5 & 2,7 & 52.166 \\
\hline $1851-55$ & 44,5 & 11,3 & 2,3 & 22,6 & 18,1 & 1,2 & 251.882 \\
\hline
\end{tabular}

solo artículo de maderas; sesenta buques con más de once mil seiscientos tirantes (o setenta mil varas) y además se han conducido a esta capital como cien mil varas en más diez y seis mil quinientas piezas, calcúlese al módico precio de 12 reales y asciende a más de doscientos cincuenta mil pesos patacones de los cuales una buena porción circula en ese Departamento, producido por el solo esfuerzo de una sexta parte de sus habitantes, porque los hombres restantes aptos para el trabajo están contraídos al pastoreo, agricultura y otros ramos de industria". El Comercio 10 de septiembre de 1854. En otro artículo (7 de noviembre de 1854) se destacaba que el gobierno realizaba erogaciones "regalando o gratificando a los indios del Chaco para que no degüellen a nuestros trabajadores de maderas".

${ }^{44}$ Tabaco paraguayo exportado por el puerto de Corrientes, 1841-1845: 15.811 arrobas (45,6\% del total de las remesas del puerto); 1846-1850: 95.928 arrobas (91,3\%); 1851-1855: 20.043 arrobas (89,4\%). 
Cuadro $\mathbf{n}^{0}$ 9. Principales productos exportados por el puerto de Bella Vista (Cantidad y $\%$ del total provincial)

\begin{tabular}{ccccccccccc}
\multicolumn{4}{c}{ Cueros } & \multicolumn{2}{c}{ Crin } & \multicolumn{2}{c}{ Tabaco } & \multicolumn{2}{c}{ Naranjas } & \multicolumn{2}{c}{ Maderas } \\
\hline Período & \multirow{2}{*}{$\mathbf{N}^{\mathbf{0}}$} & $\begin{array}{c}\mathbf{\%} \\
\text { prov, }\end{array}$ & Arrobas & $\begin{array}{c}\mathbf{\%} \\
\text { prov. }\end{array}$ & Arrobas & $\begin{array}{c}\text { \% } \\
\text { prov. }\end{array}$ & $\mathbf{N}^{\mathbf{0}}$ & $\begin{array}{c}\mathbf{\%} \\
\text { prov. }\end{array}$ & Varas & $\begin{array}{c}\text { \% } \\
\text { prov. }\end{array}$ \\
\hline $1821-25$ & 768 & $\mathbf{0 , 2}$ & - & - & 143 & $\mathbf{1 , 1}$ & 34.000 & $\mathbf{2}$ & - & - \\
\hline $1826-30$ & 11.950 & $\mathbf{8}$ & 1.546 & $\mathbf{8 , 2}$ & 1.544 & $\mathbf{5 , 7}$ & 515.628 & $\mathbf{2 2 , 9}$ & 6.520 & $\mathbf{3}$ \\
\hline $1831-35$ & 27.302 & $\mathbf{1 0}$ & 4.661 & $\mathbf{9 , 7}$ & 3.167 & $\mathbf{5 , 2}$ & 363.035 & $\mathbf{8 , 2}$ & 351 & $\mathbf{0 , 2}$ \\
\hline $1836-40$ & 7.572 & $\mathbf{3 , 2}$ & 3.738 & $\mathbf{7 , 2}$ & 1.391 & $\mathbf{4 , 3}$ & 792.600 & $\mathbf{3 3 , 6}$ & 328 & $\mathbf{0 , 3}$ \\
\hline $1841-45$ & 16.281 & $\mathbf{3 , 6}$ & 2.885 & $\mathbf{5 , 9}$ & 613 & $\mathbf{0 , 9}$ & - & - & 132 & $\mathbf{0 , 9}$ \\
\hline $1846-50$ & 37.423 & $\mathbf{3 , 3}$ & 6.468 & $\mathbf{5 , 8}$ & 639 & $\mathbf{0 , 6}$ & 1.201 .400 & $\mathbf{1 9 , 1}$ & 5.629 & $\mathbf{1 , 6}$ \\
\hline $1851-55$ & 37.588 & $\mathbf{8 , 9}$ & 10.705 & $\mathbf{1 5}$ & 2.183 & $\mathbf{6 , 2}$ & 7.044 .100 & $\mathbf{3 7 , 5}$ & 125.785 & $\mathbf{1 2 , 2}$ \\
\hline
\end{tabular}

Hasta fines de la década de 1840 , normalmente cerca del $80 \%$ del valor de las exportaciones por Bella Vista estaba integrado por cueros vacunos y otros subproductos ganaderos. Entre 1833 y 1837 funcionó un saladero en las cercanías de la localidad. ${ }^{45}$ Pese a este predominio de los frutos ganaderos el desenvolvimiento de la localidad estuvo siempre ligado a la actividad agrícola. El gobierno de la provincia había establecido este centro para agrupar a los pobladores dispersos de la campaña y con ese fin había realizado un reparto de tierras de labranza en forma gratuita ${ }^{46}$ Desde sus comienzos el cultivo del naranjo prosperó en la zona. Asimismo, como en los otros distritos de la provincia, se difundió el tabaco durante las décadas de 1820 y 1830. Superada la crisis de la guerra contra Rosas la zona de influencia de Bella Vista gozó de una etapa de crecimiento agrícola excepcional. Se convirtió en un área productora de naranjas y otros cítricos que compitió con la tradicional en torno a la ciudad de Corrientes. También se destacó el avance de la siembra comercial del maíz. Los progresos de la agricultura fueron también acompañados por un crecimiento destacable en la explotación forestal.

Cuadro n 10. Puerto de Goya. Composición de las exportaciones. ( $\%$ del valor total)

\begin{tabular}{cccccccccc} 
Período & Cueros & $\begin{array}{c}\text { Subpr. } \\
\text { Ganad. }\end{array}$ & Yerba & Tabaco & $\begin{array}{c}\text { Prods. } \\
\text { Agríc. }\end{array}$ & Maderas & $\begin{array}{c}\text { Prods. } \\
\text { Silvestres }\end{array}$ & Otros & $\begin{array}{c}\text { Total } \\
\text { pesos }\end{array}$ \\
\hline $1816-20$ & 95,5 & 4 & - & - & & - & 0,5 & - & $\mathbf{2 4 9 . 4 6 2}$ \\
\hline $1821-25$ & 79 & 3 & 11,5 & 5,5 & 0,5 & - & - & 0,5 & $\mathbf{2 1 6 . 6 8 5}$ \\
\hline $1826-30$ & 55,2 & 4,3 & 1,5 & 14,1 & 1,6 & 11,4 & 11,8 & 0,1 & $\mathbf{2 3 6 . 2 8 9}$ \\
\hline $1831-35$ & 64,5 & 15,5 & 0,4 & 11,6 & 1,1 & 1,2 & 5,5 & - & $\mathbf{3 8 3 . 6 8 3}$ \\
\hline $1836-40$ & 52,5 & 26,2 & 3,1 & 15 & 2,2 & 0,6 & 0,3 & 0,1 & $\mathbf{4 1 2 . 0 9 3}$ \\
\hline $1841-45$ & 64 & 19,3 & 3,6 & 5,8 & 0,3 & 0,3 & 0,1 & 6,6 & $\mathbf{2 5 2 . 3 8 5}$ \\
\hline $1846-50$ & 75,4 & 17,4 & 1,6 & 2,3 & 1 & 0,9 & 0,6 & 0,8 & $\mathbf{4 1 2 . 6 3 9}$ \\
\hline $1851-54$ & 62,6 & 22,4 & 5 & 5,2 & 1,3 & 1,6 & 0,5 & 1,1 & $\mathbf{3 7 6 . 0 2 7}$ \\
\hline
\end{tabular}

${ }^{45} A G P C, E A$, leg. 36. Autorización a Tomás Isasi para la libre introducción de sal para su establecimiento (3 de agosto de 1833).

${ }^{46} R O$, tomo I, 1821-1825, p. 382. 
Cuadro $\mathbf{n}^{0}$ 11. Principales productos exportados por el puerto de Goya (Cantidad y \% del total provincial)

\begin{tabular}{ccccccccccc} 
& \multicolumn{2}{c}{ Cueros } & \multicolumn{2}{c}{ Crin } & \multicolumn{2}{c}{ Grasa } & \multicolumn{2}{c}{ Tabaco } & \multicolumn{2}{c}{ Yerba } \\
\cline { 2 - 13 } & $\mathrm{N}^{\mathbf{0}}$ & $\%$ prov. & arrobas & \% prov. & arrobas & \% prov. & arrobas & \% prov. & arrobas & $\%$ \\
\hline $1816-20$ & 345.059 & $\mathbf{5 9 , 6}$ & 8.093 & $\mathbf{5 2 , 7}$ & - & - & - & - & - & - \\
\hline $1821-25$ & 188.311 & $\mathbf{5 7 , 6}$ & 6.933 & $\mathbf{3 6 , 6}$ & - & - & 1.529 & $\mathbf{1 2 , 3}$ & 4.810 & $\mathbf{3 8}$ \\
\hline $1826-30$ & 73.438 & $\mathbf{4 9}$ & 6.260 & $\mathbf{3 3 , 3}$ & - & - & 3.448 & $\mathbf{1 2 , 6}$ & 218 & $\mathbf{1 , 4}$ \\
\hline $1831-35$ & 101.563 & $\mathbf{3 7 , 5}$ & 17.643 & $\mathbf{3 6 , 6}$ & 488 & $\mathbf{1 5 , 2}$ & 8.612 & $\mathbf{1 4 , 1}$ & 309 & $\mathbf{2 , 7}$ \\
\hline $1836-40$ & 118.628 & $\mathbf{4 9 , 5}$ & 23.930 & $\mathbf{4 5 , 8}$ & 8.228 & $\mathbf{4 7 , 1}$ & 8.193 & $\mathbf{2 5 , 4}$ & 4.302 & $\mathbf{7 7 , 2}$ \\
\hline $1841-45$ & 134.337 & $\mathbf{2 9 , 8}$ & 20.060 & $\mathbf{4 1}$ & 11.261 & $\mathbf{7 4 , 1}$ & 5.497 & $\mathbf{8 , 3}$ & 2.549 & $\mathbf{4 , 3}$ \\
\hline $1846-50$ & 331.616 & $\mathbf{2 9 , 5}$ & 35.621 & $\mathbf{3 2 , 1}$ & 11.584 & $\mathbf{9 1 , 9}$ & 1.599 & $\mathbf{1 , 4}$ & 5.472 & $\mathbf{3 , 4}$ \\
\hline $1851-55$ & 120.323 & $\mathbf{2 8 , 3}$ & 23.842 & $\mathbf{3 2 , 2}$ & 12.847 & $\mathbf{4 4 , 2}$ & 9.370 & $\mathbf{2 6 , 8}$ & 8.175 & $\mathbf{1 2 , 5}$ \\
\hline
\end{tabular}

Como cabecera mercantil de la zona ganadera del sur, las exportaciones por el puerto de Goya tenían un neto predominio de frutos pecuarios. Hasta fines de la década de 1830 fue la plaza de donde se extraía la mayor cantidad de cueros vacunos y equinos por año. Esta preeminencia desapareció en el decenio de 1840, dado que las remesas por el puerto de la capital y otras plazas tendieron a crecer mientras que las de Goya, salvo algunos años excepcionales, se mantuvieron estancadas. En relación con el comercio de otros subproductos ganaderos, el aporte de Goya fue siempre considerable. Como en otras zonas, un crecimiento importante se produjo desde principios de la década de 1830 por la recuperación ganadera y la instalación, en 1834, de un establecimiento destinado a la elaboración de carne salada, grasa, sebo y otros frutos pecuarios. La actividad de la empresa se concentró en la elaboración de grasa, aceite de potro y tocino. La grasería continuó operando hasta 1843 , reanudó sus tareas en 1848 y todavía se mantenía activa a mediados de la década de $1850 .{ }^{47}$

Asimismo, por el puerto de Goya se exportaban cantidades variables de frutos agrícolas, maderas y pieles de animales silvestres. Aún cuando la actividad agrícola no estaba muy desarrollada en el sur ganadero, en torno a Goya y otras poblaciones existían zonas más o menos extensas destinadas al cultivo. Las remesas de tabaco constituyeron un aporte apreciable en el total provincial durante las décadas de 1820 y 1830 . Esta contribución se amplió aún más durante los primeros años del decenio de 1850, dado que la producción de tabaco de la zona de Goya tendió a crecer, si bien moderadamente, mientras que la del noroeste sufría una fuerte reducción. En el quinquenio de 1851-1855 por Goya se extrajo cerca del $27 \%$ del volumen de tabaco exportado por la provincia. Hay que tener en cuenta, sin embargo, que en el total provincial cerca del $58 \%$ correspondía a partidas de tabaco paraguayo que se reenviaban por el puerto de Corrientes. Si se tiene en cuenta sólo las remesas del tabaco de la provincia, las exportaciones por Goya

\footnotetext{
${ }^{47}$ Leyes del 31 de octubre de 1834 y 27 de enero de 1835 sobre el fomento de Saladeros, $R O$, tomo III, 1831-1837, p 230 y 268; decreto del 2 de julio de 1848 sobre el funcionamiento de graserías, $R O$, tomo VI, 1847-1852, p. 108; Mackinnon, 1957; 154-159. También dentro del comercio de frutos pecuarios por el puerto de Goya hay que destacar la exportación de quesos que constituía una peculiaridad de la zona. La elaboración tenía una larga tradición pero la venta a otros distritos recién se afianzó a principios de la década de 1830. A mediados del siglo XIX se exportaban anualmente alrededor de 34.000 unidades.
} 
alcanzaban a cerca del $63 \%$ del total. Esto indicaba que la zona de cultivo de tabaco más importante se había desplazado del noroeste hacia el sudoeste de la provincia.

Cuadro $\mathbf{n}^{\circ}$ 12. Puerto de Esquina. Composición de las exportaciones. (\% del valor total)

\begin{tabular}{|c|c|c|c|c|c|c|c|c|c|}
\hline & Cueros & $\begin{array}{c}\text { Subprod. } \\
\text { ganaderos }\end{array}$ & $\begin{array}{c}\text { Animales } \\
\text { En pie }\end{array}$ & Yerba & $\begin{array}{c}\text { Prods. } \\
\text { agrícolas }\end{array}$ & Maderas & $\begin{array}{c}\text { Prods. } \\
\text { silvestres }\end{array}$ & Otros & $\begin{array}{c}\text { Total en } \\
\text { pesos }\end{array}$ \\
\hline $1816-20$ & 96,8 & 3,2 & - & - & - & - & - & - & 11.445 \\
\hline $1821-25$ & 89,5 & 1,2 & 6 & - & 0,8 & 0,6 & 0,3 & 1,6 & 18.985 \\
\hline $1826-30$ & 57,5 & 1 & 2,8 & - & 4,7 & 13,3 & 20,7 & - & 24.857 \\
\hline $1831-35$ & 56,7 & 7,7 & 2,4 & 20,9 & 1,8 & 1,2 & 8,9 & 0,4 & 100.792 \\
\hline $1836-40$ & 57,7 & 28,1 & 1,5 & 8,6 & 1 & 0,3 & 2,8 & - & 50.785 \\
\hline $1846-50$ & 40,9 & 35,1 & 12,2 & - & 2,2 & 4,4 & 5,2 & - & 7.971 \\
\hline $1851-55$ & 42,3 & 19,2 & 10,6 & - & 2,5 & 22,2 & 3,2 & - & 29.565 \\
\hline
\end{tabular}

Cuadro no 13. Principales productos exportados por el puerto de Esquina (Cantidad y \% del total provincial)

\begin{tabular}{ccccccc} 
& \multicolumn{2}{c}{ Cueros } & \multicolumn{2}{c}{ Crin } & \multicolumn{2}{c}{ Yerba } \\
\cline { 2 - 7 } & $\mathbf{N}^{\mathbf{0}}$ & $\begin{array}{c}\text { \% de la } \\
\text { provincia }\end{array}$ & Arrobas & $\begin{array}{c}\text { \% de la } \\
\text { provincia }\end{array}$ & arrobas & $\begin{array}{c}\text { \% de la } \\
\text { provincia }\end{array}$ \\
\hline $1816-1820$ & 19.443 & $\mathbf{3 , 4}$ & 419 & $\mathbf{2 , 7}$ & - & - \\
\hline $1821-1825$ & 17.254 & $\mathbf{5 , 2}$ & 287 & $\mathbf{1 , 5}$ & - & - \\
\hline $1826-1830$ & 5.969 & $\mathbf{4}$ & 158 & $\mathbf{0 , 8}$ & - & - \\
\hline $1831-1835$ & 28.740 & $\mathbf{1 0 , 6}$ & 3.122 & $\mathbf{6 , 5}$ & 5.471 & $\mathbf{4 7 , 5}$ \\
\hline $1836-1840$ & 11.218 & $\mathbf{4 , 7}$ & 2.486 & $\mathbf{4 , 8}$ & 1.189 & $\mathbf{2 1 , 3}$ \\
\hline $1846-1850$ & 2.656 & $\mathbf{0 , 2}$ & 398 & $\mathbf{0 , 4}$ & - & - \\
\hline $1851-1855$ & 4.585 & $\mathbf{1 , 1}$ & 839 & $\mathbf{1 , 1}$ & - & - \\
\hline
\end{tabular}

En lo que respecta a Esquina, además de la exportación de cueros y otros subproductos, también tuvo alguna intervención en la venta de animales en pie hacia Entre Ríos y Brasil. Asimismo la plaza contribuyó de manera significativa en la salida de pieles de nutria durante el auge del comercio de este producto. ${ }^{48}$

Por los puertos de Goya y Esquina desde principios de la década de 1820 también se exportaba yerba mate, principalmente de origen brasileño, que ingresaba por el sector oriental de la provincia. De todas formas la reventa de yerba brasilera no alcanzó nunca el volumen del comercio de la yerba paraguaya.

\footnotetext{
${ }^{48}$ Entre 1826 y 1835 se exportaron por el puerto alrededor de 88.000 pieles que representaron cerca del $13 \%$ de total provincial.
} 
Cuadro no 14. Puertos de la zona del Uruguay. Composición de las exportaciones (\% del valor total)

\begin{tabular}{ccccccccc} 
& Cueros & Suelas & $\begin{array}{c}\text { Subprod. } \\
\text { ganaderos }\end{array}$ & $\begin{array}{c}\text { Animales } \\
\text { en pie }\end{array}$ & Yerba & Tabaco & Otros & $\begin{array}{c}\text { Total } \\
\text { en pesos }\end{array}$ \\
\hline $1821-25$ & 47,5 & - & 3,1 & 49,4 & - & - & - & $\mathbf{1 1 . 2 6 5}$ \\
\hline $1826-30$ & 26,1 & - & 2,5 & 70,7 & - & - & 0,7 & $\mathbf{2 6 . 7 3 6}$ \\
\hline $1831-35$ & 3 & - & - & 93,5 & - & 3 & 0,5 & $\mathbf{4 5 . 4 7 6}$ \\
\hline $1836-40$ & 21,6 & - & 1,7 & 71,7 & - & 1,4 & 3,6 & $\mathbf{1 9 . 7 2 4}$ \\
\hline $1841-45$ & 34 & 2,4 & 9,1 & 22,1 & 10,2 & 20 & 2,2 & $\mathbf{3 7 1 . 4 5 1}$ \\
\hline $1846-50$ & 30,7 & 1,8 & 7,4 & 38,3 & 4,1 & 4,4 & 13,3 & $\mathbf{1 5 9 . 3 8 2}$ \\
\hline $1851-55$ & 45,7 & - & 14,5 & 37,9 & 0,5 & 1,1 & 0,3 & $\mathbf{2 1 7 . 5 1 8}$ \\
\hline
\end{tabular}

Cuadro $\mathbf{n}^{\mathbf{0}}$ 15. Principales exportaciones por los puertos de la zona del Uruguay (Cantidad y \% del total provincial)

\begin{tabular}{ccccccccccc} 
& \multicolumn{2}{c}{ Cueros } & \multicolumn{2}{c}{ Caballos } & \multicolumn{2}{c}{ Vacunos } & \multicolumn{2}{c}{ Tabaco } & \multicolumn{2}{c}{ Yerba } \\
\cline { 2 - 11 } & $\mathbf{N}^{\mathbf{0}}$ & $\begin{array}{c}\mathbf{\%} \\
\text { Prov. }\end{array}$ & $\mathbf{N}^{\mathbf{0}}$ & $\begin{array}{c}\mathbf{\%} \\
\text { Prov. }\end{array}$ & $\mathbf{N}^{\mathbf{2}}$ & $\begin{array}{c}\mathbf{\%} \\
\text { Prov. }\end{array}$ & arrobas & $\begin{array}{c}\text { \% } \\
\text { Prov. }\end{array}$ & arrobas & $\begin{array}{c}\text { \% } \\
\text { Prov. }\end{array}$ \\
\hline $1821-25$ & 6.185 & $\mathbf{1 , 9}$ & - & - & - & - & - & - & - & - \\
\hline $1826-30$ & 3.387 & $\mathbf{2 , 3}$ & 2.873 & $\mathbf{5 9}$ & - & - & - & - & - & - \\
\hline $1831-35$ & - & - & 6.791 & $\mathbf{9 2}$ & 6.883 & $\mathbf{7 9 , 1}$ & - & - & - & - \\
\hline $1836-40$ & 722 & $\mathbf{0 , 2}$ & 2.949 & $\mathbf{9 4}$ & 1.232 & $\mathbf{9 2 , 4}$ & - & - & - & - \\
\hline $1841-45$ & 99.581 & $\mathbf{2 2 , 1}$ & 4.639 & $\mathbf{6 2 , 2}$ & 19.048 & $\mathbf{9 7 , 7}$ & 24.950 & $\mathbf{3 7 , 8}$ & 18.234 & $\mathbf{3 1}$ \\
\hline $1846-50$ & 53.074 & $\mathbf{4 , 9}$ & 7.266 & $\mathbf{6 8 , 5}$ & 17.506 & $\mathbf{9 6 , 5}$ & 3.489 & $\mathbf{3 , 2}$ & 7.193 & $\mathbf{4 , 4}$ \\
\hline $1851-55$ & 37.567 & $\mathbf{8 , 9}$ & 5.885 & $\mathbf{5 4}$ & 17.168 & $\mathbf{9 5 , 7}$ & 1.049 & $\mathbf{2 , 8}$ & 1.144 & $\mathbf{1 , 8}$ \\
\hline
\end{tabular}

Durante la primera mitad del siglo XIX el comercio en el sector oriental de la provincia, con una base productiva todavía débil, se fundaba en la venta de frutos ganaderos y la reexportación de tabaco del Paraguay y de yerba brasileña y paraguaya. La venta de cueros y otros subproductos, adquirió cierta magnitud en la década de 1840 cuando la clausura del Paraná obligó a utilizar vías alternativas. En el área tenía un papel preponderante la venta de ganado en pie. Ésta se inició a principios de la década de 1820 con la extracción de mulas. A mediados del decenio se sumó la venta de caballos y yeguas, y a principios de la década siguiente el gobierno autorizó la exportación de vacunos. El comercio se centralizaba por la localidad de Curuzú Cuatiá y el destino principal de las remesas era el Brasil aunque ocasionalmente también se vendió ganado vacuno a la provincia de Entre Ríos. De todas formas, el tráfico era todavía reducido y con un mercado limitado. La situación comenzó a cambiar en la primera mitad de la década de 1850 porque la demanda de los saladeros de los Estados vecinos abrió mayores posibilidades para el futuro. Así en 1853 el tráfico de hacienda, sobre todo vacuna, por Paso de los Libres con destino al Brasil aumentó de manera excepcional aunque al año siguiente se paralizó. Asimismo, Curuzú Cuatiá fue la plaza de salida de partidas regulares de equinos y vacunos con destino al nordeste entrerriano. ${ }^{49}$

\footnotetext{
${ }^{49}$ En El Comercio se señalaba (7 de septiembre de 1856) que uno de los ramos de comercio de Restauración
} [Paso de los Libres] "ha sido la exportación de la hacienda que la provincia vendía para el Imperio, y 
Con la fundación de Santo Tomé y Paso de los Libres la provincia pudo acceder a los circuitos de la yerba en la zona del Alto Uruguay. (Poenitz, 1981; 28-32; Schmit, 2004, 139-149). El tráfico de esta región, en gran medida clandestino, tenía como centros de exportación a Encarnación (Itapúa hasta 1842), San Borja e Itaquí, y como plazas de depósito y distribución hacia los mercados del sur, a Concordia y Salto. Entre 1842 y 1846 Santo Tomé constituyó un centro muy activo como el punto de tránsito de la yerba y el tabaco paraguayos en la ruta de Encarnación a San Borja. Por el puerto de Paso de los Libres se reexportaba yerba proveniente del Brasil o de las altas Misiones. Sin embargo, el volumen de las remesas era reducido ya que la localidad era un lugar de paso para el tráfico hacia Concordia.

\section{Conclusiones}

Durante la primera mitad del siglo XIX el río Paraná fue la principal vía del comercio exterior de la provincia de Corrientes. Esta ruta fluvial, pese a sus limitaciones, constituía para las condiciones de la época un medio rápido y económico que vinculaba el área más densamente poblada y productiva de la provincia con los centros del sur en especial con Buenos Aires, principal destino de los frutos locales y centro proveedor de manufacturas y de crédito.

A lo largo de esta etapa la región noroeste concentró la actividad productiva y comercial de la provincia. El valor del tráfico del puerto de Corrientes, la ciudad cabecera, fue superior al de todos los otros centros habilitados en conjunto. El predominio se debía en gran medida a sus excelentes condiciones naturales para el acceso de los buques de la navegación fluvial y aún los de ultramar. Esta ventaja lo convertía en el mejor punto de contacto con otras regiones y compensaba en gran parte el relativo aislamiento de la ciudad con respecto al resto de la jurisdicción. Asimismo, por su situación estratégica en la boca del río Paraguay, en las particulares condiciones políticas de la época, durante algunos períodos logró canalizar gran parte del comercio exterior de esa república.

Por el volumen de su actividad comercial, el puerto de Goya seguía en importancia al de Corrientes. Era la cabecera mercantil de una vasta zona ganadera del centro y del sur de la provincia por lo que concentraba un alto porcentaje de sus exportaciones pecuarias. No obstante, su crecimiento estuvo siempre condicionado por las dificultades de acceso al puerto y las sucesivas crisis bélicas por las que atravesó la provincia que tuvieron por escenario principal la zona ganadera del sur. En particular, el largo conflicto contra Rosas tuvo efectos destructivos y frenó el crecimiento de la actividad pecuaria que se venía manifestando en la década de 1830 .

De las otras localidades habilitadas sobre el Paraná, el puerto de Bella Vista fue el de mayor desarrollo comercial. Surgió como centro alternativo para las zonas

que venían todas a cruzar el Uruguay por este puerto que... da vado en muchas ocasiones... Esto atraía a su mercado a un número considerable de compradores y peonadas introduciendo crecidísimas sumas de metálico..." se destacaba, no obstante que "La extracción de ganado para el Imperio ha cesado casi desde que el cólera afligió esta parte del Imperio ante cuyo flagelo, los saladeros han tenido que cerrar sus puertas...". 
del noroeste de la provincia. Su desenvolvimiento se vio favorecido por su excelente ubicación y el crecimiento productivo en su área de influencia. Por su parte, la localidad de Esquina constituía el punto de contacto con el exterior de un área ganadera relativamente aislada del extremo suroeste de la provincia. En 1840 fue destruida por fuerzas invasoras y no logró recuperar su actividad hasta los primeros años de la década de 1850 .

Durante la primera mitad del siglo XIX el sector de la provincia sobre la vertiente del Alto Uruguay constituía todavía una vasta frontera débilmente ocupada y con escaso control estatal. Los saltos rocosos al norte de Concordia que limitaban la navegación hacia los centros del sur contribuían al aislamiento de la zona. La actividad mercantil se centraba en el intercambio fronterizo con los distritos vecinos, principalmente con el Brasil y el nordeste entrerriano. El volumen de este comercio era reducido dentro del total de la provincia aún si tiene en cuenta el activo contrabando en el área. Sólo durante la primera mitad de la década de 1840 la participación del intercambio por el río Uruguay creció de manera significativa a raíz del bloqueo del Paraná. Una vez que se regularizó la navegación por esa vía fluvial el tráfico en el sector oriental ocupó nuevamente un papel secundario. A mediados del siglo XIX los centros de mayor actividad en el área fueron la localidad de Curuzú Cuatiá vinculada con el nordeste de Entre Ríos y Paso de los Libres para el intercambio con el Brasil.

\section{Referencias bibliográficas}

Arbo, H. 1939. Libre navegación de los ríos, régimen jurídico de los ríos de la Plata, Paraná y Paraguay, Buenos Aires.

Bruniard, E. 1966. "Bases fisiogeográficas para una división regional de la provincia de Corrientes", Nordeste, Nº 8, Resistencia, UNNE, pp. 7-80.

Buchbinder, P. 2004. Caudillos de pluma y hombres de acción. Estado y política en Corrientes en tiempos de la organización nacional, Buenos Aires, Prometeo

Burgin, M. 1975. Aspectos económicos del federalismo argentino, $2^{\circ}$ reimpresión, Buenos Ares, Solar/Hachette.

Centeno, M. T. 1980. "San Juan del Hormiguero. Crónica de su origen y desarrollo. Antecedentes de la refundación de Santo Tomé" Primer encuentro de Geohistoria Regional, Corrientes, IIGHI, pp.132-133

Chiaramonte, J. C. 1991. Mercaderes del Litoral. Economía y sociedad de la provincia de Corrientes. Primera mitad del siglo XIX, Buenos Aires, Fondo de Cultura Económica

D’Orbigny, A. 1955. Viaje por América meridional, Buenos Aires, Madrid, Aguilar.

Duarte, M.A. 1966. "Artigas y el comercio del río Paraná hasta la reunión del Congreso", Trabajos y Comunicaciones, $\mathrm{n}^{\mathrm{o}} 15$.

Gómez, H. 1928. Historia de la provincia de Corrientes. De la revolución de Mayo hasta el tratado del Cuadrilátero, Corrientes, Imprenta del Estado. 
Gómez, H. 1944. La ciudad de Corrientes. Turismo, economía. Información. Historia. Geografía.

Gutiérrez, R. y Sánchez Negrette, A. 1988. Evolución urbana y arquitectónica de Corrientes, Buenos Aires.

Kroeber, C. B. 1967. La navegación de los rios en la historia Argentina, 1794-1860, Buenos Aires, Paidos.

Maeder, E. J. A. 1969. Evolución demográfica argentina desde 1810 a 1869, Buenos Aires, Eudeba.

Maeder, E. J. A. 1981. Historia económica de Corrientes en el período virreinal 17761810, Academia Nacional de la Historia.

Mackinnon, L. B. 1957. La escuadra anglo-francesa en el Paraná, 1846, trad. José Luis Busaniche, Buenos Aires.

Mantilla, M. F. 1928. Crónica histórica de la provincia de Corrientes, tomo II, Corrientes.

Moussy, V. M. de. 1860. Description géographique et statistique de la Confédération Argentine, tomo III.

Palma, F. 1969. "Santo Tomé Crónica de su restablecimiento", Revista de la Junta Historia de Corrientes, $\mathrm{n}^{\mathrm{o}}$ 4, pp. 20-47.

Pérez, M. E. 1989. "La ciudad de Corrientes: puerto de escala en la ruta fluvial del Paraná. Aportes a su historia" Páginas correntinas, Año I, tomo I, Corrientes.

Poenitz, E. 1981. "La ruta oriental de la yerba. Navegación y comercio en alto río Uruguay", Revista de Estudios Regionales, № 1, Concordia.

Robertson, G. P. y J. Parish. 1950. Cartas de Sud-América, traducción José Luis Busaniche, Buenos Aires, Emecé.

Rivera, A. 1988. El comercio de cabotaje desde el puerto de Corrientes. Exportaciones entre 1848-1855, Cuadernos de Estudios Regionales, $n^{\circ}$ 7, Concordia.

Rosal, M. A. y Schmitt, R. 1994. "Las exportaciones del Litoral argentino al puerto de Buenos Aires entre 1783-1850”, Revista de Historia Económica, XIII, 3.

Salvatore, Ricardo, 1995. "The Breakdown of Social Discipline in the Banda Oriental and the Littoral", Szuchman, Mark and Brown, Jonathan, Revolution and Restoration: the Rearrangement of Power in Argentina 1776-1860, University of Nebraska, pp. 74-102.

Scavone Yegros, R. 1995. "Los Tratados de 1841 entre el Paraguay y Corrientes", Estudios Paraguayos, vol. XVIII, n 1-2.

Schmit, R. 2004. Ruina y resurrección en tiempos de guerra. Sociedad, economía y poder en el oriente entrerriano postrevolucionario. 1810-1852, Buenos Aires, Prometeo.

Wentzel, C. 1988. "El comercio del litoral de los ríos con Buenos Aires: el área del Paraná (1783-1988), Anuario IEHS, nº 3, Tandil.

Whigham. T. 2009. Lo que el río se llevó. Estado y comercio en Paraguay y Corrientes 1776-1870, Asunción, Centro de Estudios Antropológicos de la Universidad Católica. 